\title{
Power Control Energy Management and Market Systems
}

December 20, 2005 


\section{Award Identification}

Project Title: Power Control Energy Management and Market Systems

Covering Period: July 7, 2004 through September 30, 2005

Date of Report: December 15, 2005

Recipient: AREVA T\&D Inc.

11120 NE 33rd Place

Bellevue, WA 98004

Award Number: DE-FC02-03CH11162

Subcontractors:

Sempra Energy Solutions (SES)

Contact(s): Andrew Stanbury, Principal Investigator 425-739-3385, andrew.stanbury@areva-td.com 11120 NE 33rd Place

Bellevue, WA 98004

Tom Addison, Principal Project Manager

425-739-3344, thomas.addison@areva-td.com

11120 NE 33rd Place

Bellevue, WA 98004 


\section{TABLE OF CONTENTS}

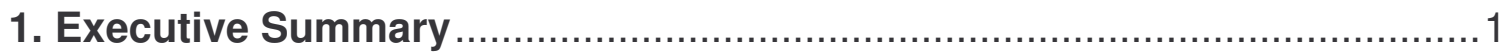

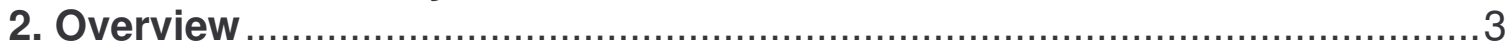

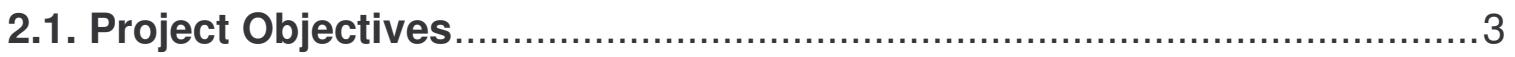

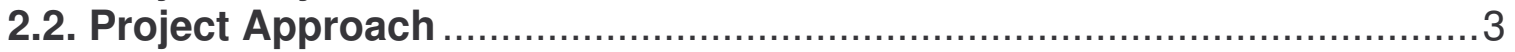

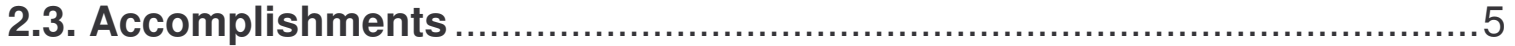

2.3.1. Document Energy Marketers Requirements................................... 5

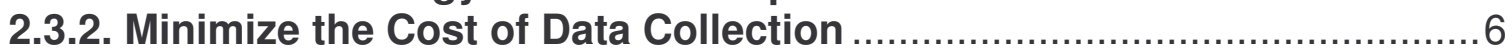

3. Functional Summary of the Advanced C\&C System ........................... 7

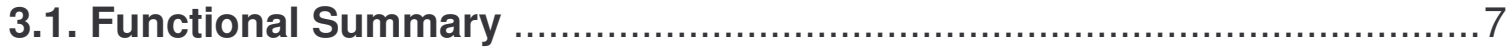

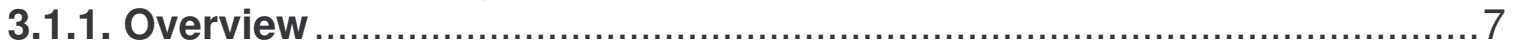

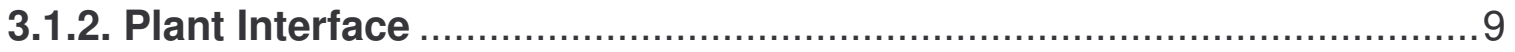

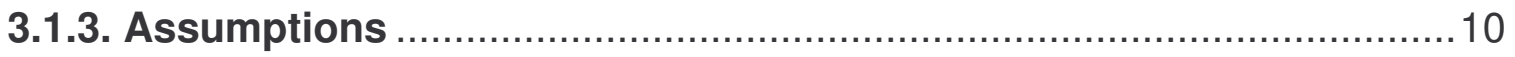

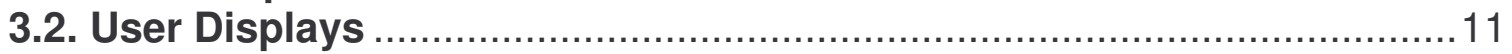

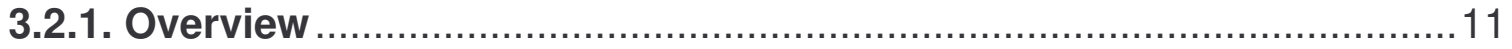

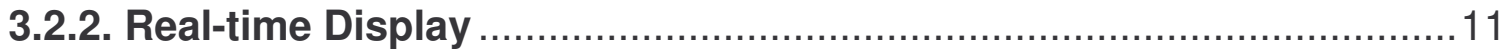

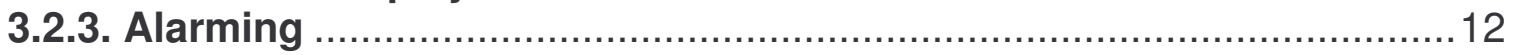

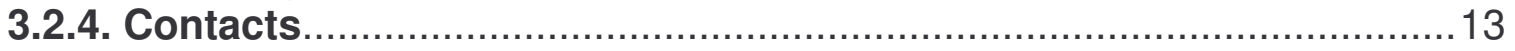

3.2.5. Market Price and Metered Usage Details .................................. 14

3.2.6. User Access Administration ....................................................... 15

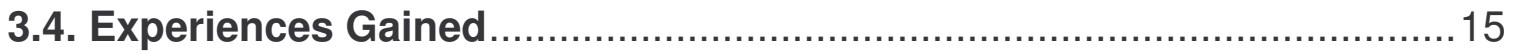

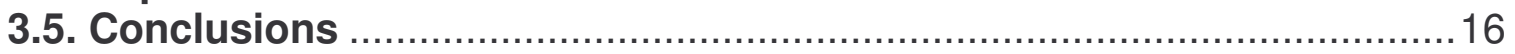

APPENDIX A - SEMPRA ENERGY SERVICES DESIRED FUCTIONS OF A MARKET DRIVEN RETAIL ENERGY RISK MANAGEMENT SYSTEM

APPENDIX B - METER DATA COLLECTION OVER WAN WITH e-terracontrol

APPENDIX C - CONFIGURATION TECH NOTE - COMTROL DEVICEMASTER PRO "SOCKET SERVER" 


\section{Executive Summary}

AREVA T\&D (AREVA) and its partners are pleased to submit this report on the team's approach to expand and enhance the advanced communication and control technologies and architectures that facilitate large-scale integration of Distributed Energy Resources (DER) with electricity markets and power systems.

At project initiation, the legacy advanced communication and control system developed in the Phase I project required work to be restarted. Once restarted, Sempra was notified how to access the system and that AREVA was interested in getting Sempra's feedback on how to enhance the system to meet their requirements.

The project team determined the best way to execute was to concentrate in two areas of interest. These two areas of interest are requirements collection and minimizing the cost of deployment of data collection systems.

A kick off meeting was held with Sempra to hear how their business model had changed since the previous project. During this meeting we agreed that representatives from both Sempra and AREVA would exchange ideas and AREVA would create a document that captured Sempra's functional requirements. This document was not intended to be a requirements document for this project but instead to record functionality that would be part of a future system.

In parallel with this requirements collection with Sempra, AREVA investigated to determine if new equipment existed to make data collection easier (less expensive) to install in an industrial plant or factory.

After reviewing the Sempra requirements document it was clear the existing proof of concept computer system would need significant modification to approach this functionality. The work to develop a computer system that would meet the requirements described in the Sempra document was estimated. This estimate required much more labor resources than was available in the project budget.

The project experienced a set back when Sempra underwent a reorganization that resulted in its withdrawal from the project. In December 2004 Ali Ipakchi (Principal Investigator) resigned from AREVA and was replaced by Andrew Stanbury. In January 2005, Renee Guild and Angela Chuang left the company and were not replaced.

The new Principle Investigator evaluated the project status and initiated new concepts to determine if there were ways to utilize the resources of the project to find ways to modify electrical consumption of commercial and industrial users.

Some of the new ideas included:

1. Contacted an affiliate company in the UK to determine the applicability of their systems for this project. It was determined that the systems that had been developed for use by traders in the UK electricity and gas markets were indeed appropriate and work started to upgrade the prior POC system by incorporating the systems from the UK. The difficulty remained to find industry partners to proceed with the project. 
2. Contacted Bio-Radiant Corporation to determine the degree of harmony between their products and the project. The Bio-Radiant Ice Battery has two or more heat exchangers surrounded with water. During off-peak hours, a cooling system cools the water until it freezes. The Ice Battery stores thermal energy for use during periods of peak electrical usage. When this occurs, refrigeration and air conditioning compressors are turned off and the Ice Battery provides cooling necessary to continue operation. This load shifting technology is available today.

3. Contacted Safeway Corporate office to determine their interest in participating in the project. Safeway has a variety of contracts for supply of energy, and has an attractive load factor for energy supply companies. As far as Safeway was concerned, they were happy with their present arrangements and saw no benefit in engaging in a load management program.

4. Contacted Costco Corporate office with the same objective as the Safeway contact reported above. The outcome was the same as with Safeway.

5. Contacted Los Angeles County (LA County) to investigate the work being done by LA County to manage the electrical consumption of County owned buildings (libraries, fire stations, etc.) and public housing tenants. LA County monitors their energy usage, along with all the factors that affect the load. The monitoring performed was far more extensive than the monitoring contemplated by the project. In essence, the monitoring consisted of the integration of a diverse set of individual building management systems,

6. AREVA explored a relationship with EnerNOC to help expand the penetration of emergency load response in the reliability arena. This was presented to DOE at the April Meeting in Atlanta. DOE determined that this represented an activity that was already commercially viable and thus did not fit with the DOEs research objectives of developing new and innovative approaches to load management.

Each of these ideas was determined to be infeasible and the project went dormant. 


\section{Overview}

\subsection{Project Objectives}

The purpose of this project is to expand the customer base and to build upon the proof of concept system designed, developed and demonstrated in an earlier DOE project (Phase I). In Phase I AREVA designed, developed and demonstrated an Advanced Communications and Control (C\&C) Systems that enabled retail energy companies to capture value at both end-use and power system levels, minimize operating risks, and maximize benefits through coordinated operation of distributed energy resources (DER) in multiple markets and ISO regions.

The Phase II project's objective is to build upon that earlier work by building a network of computers to collect real time electrical usage information and to expand the capabilities of the software to increase the participation of retail energy marketers utilizing this C\&C system.

The objective of this project is to improve and demonstrate advanced communications and control systems that enable retail energy companies to capture value at end-use and power system levels, minimize operating risks and maximize benefits through coordinated operation of Distributed Energy Resources (DER).

Specifically objectives of this project are to extend the capabilities developed during the Phase I Proof of Concept by:

- Improve and expand the data acquisition and market interfaces of the Resource Management System (RMS), developed in Phase I, to integrate data from additional facilities and ISO markets, to provide for robust data management, integration of decision support and other applications;

- Design, develop and implement a energy retailer's decision support application aimed to minimize the overall cost of electrical supply to a portfolio of customers by providing "realtime" visibility to demand and market conditions, and by managing risks associated with real-time balancing of supply and demand through improved efficiency and flexibility of scheduling and portfolio management operation.

- Demonstrate the above applications with select customers in the PJM and ERCOT regions through scheduling supply, demand and other available resources, and by management of energy and imbalance charges.

\subsection{Project Approach}

The chosen approach to achieving the project objectives is to demonstrate at a national level integration of DER with power system and market operations, with an emphasis on large commercial and industrial (C\&I) customers. Existing resources across various RTO/ISO and utility jurisdictions were identified as demonstration sites. Heavy emphasis was placed on market integration of DER, because markets are where values to be captured originate.

The project approach is multi-faceted, recognizing the integral relationship between technology, economics, and policy. That is, integration of DER into power system operations is inherently an economic problem driving a technical problem, along with industry practices and policy also influencing economics. To better capture sustainable value in such an 
environment, the approach for proof-of-concept was to demonstrate national large scale integration of DER with power systems and electricity market operations. AREVA T\&D Corp (AREVA) assembled a team capturing the ideal business drivers for achieving the proposed objectives. Host energy retailer and end-use facilities included national retail energy operations across multiple ISO jurisdictions, through which higher potential value capture could be demonstrated.

Competitive energy retailers like Sempra Energy Solutions (SES) are undoubtedly incentivized to innovate but require shorter pay-back timeframes than normally can be achieved by projects involving installation of advanced C\&C systems. Although they are ideal candidates to demonstrate value capture through coordinated utilization of DER, competitive energy retailers like SES generally lack visibility of customer resources. Consequently, the project provides connectivity to end-use resource and market visibility for an energy retailer to tap existing DER potential among its customers. Tools that integrate customer usage data with market data are reportedly extremely useful in coordinating real-time operations.

The chosen direction and objective of this project is based on the premise that the power systems industry at large has not produced a comprehensive view of the multitude of stakeholder interactions and issues within each layer of interaction that takes place. Yet it is essential not to mix issues in the intra-energy retailer layer, for example, with issues in the end-user layer or utility grid operations layer. Rather, an architectural reference model is needed that differentiates where data requirements are extensive from where they are not. Furthermore, existing practices and communications protocols prevalent in industry must be taken into account and not ignored.

Basic requirements of the $\mathrm{C} \& \mathrm{C}$ information system

1. Collect real time energy usage information at end user locations in a central location.

2. Collect day ahead (forecasted) electrical pricing information from multiple ISOs.

3. Collect real time electrical pricing information from multiple ISOs.

4. Notify retail energy marketers when defined opportunities occur.

To reduce installation costs at remote facilities (load centers) a procedure will be documented on how to install an intelligent meter that can be read over the internet. These step by step instructions will describe the equipment necessary, installation and configuration procedures to enable the meter to be read over the internet. This intelligent meter can be read over the internet when connected to a terminal server device connected to the internet. A computer with e-terracontrol installed and connected to the internet will read the intelligent meter located in a remote location such as a industrial plant or factory. This computer will monitor electrical measurements and other information to determine when an economic opportunity exists. Economic opportunity will be defined by the user. This system will also be used to determine compliance with an agreement is being adhered to.

The Internet is used to provide connectivity between energy users, energy marketers and the C\&C system. Using web pages retail marketers will define opportunities that will be determined based on information collected by the C\&C system. These defined conditions are evaluated continuously. When a defined condition exists, the C\&C system sends an email to a specified email address (or text pager). The receiver of this message (typically an energy marketer) determines how they will respond to the opportunity. For example, if the real time price of electrical energy in a particular market exceeds the day ahead price by $20 \%$, the energy marketer may offer an incentive to the energy user to curtail a portion of their load for a specified period. If the energy user agrees, the C\&C system will continue to monitor the system. If the price of electrical energy drops to $80 \%$ of the day ahead price, the energy marketer may release the energy user from the agreement made earlier. 


\subsection{Accomplishments}

\subsubsection{Document Energy Marketers Requirements}

Early in the project members of the project team met with representatives from Sempra. During this meeting it was determined that the existing proof of concept computer system lacked several functions to give Sempra a competitive advantage in the marketplace.

To address this lack of function, Sempra agreed to provide information on how data could be used to control costs and determine economic viability. A representative from AREVA spent several days discussing and documenting Sempra's approach to control costs and determine economic viability.

This paper titled Sempra Energy Services Desired Functions of a Market-Driven Retail Energy Risk Management System describes the functions of a Retail Risk Management (RRM) system that an Energy Retailer serving as an Aggregator, can use to better serve the electric supply needs of large Commercial and Industrial customers. The document is not intended to construe a commitment of delivery of these functions. Instead, it was intended to capture the desired functions for consideration when designing a future RRM.

The Retail Energy business is exposed to market risks that cannot be fully mitigated. They sell electric energy, capacity, and ancillary services and purchase fuel through short and long-term contracts or spot markets. Therefore the financial results from operations and cash flows depend on prevailing market prices for electricity and fuel markets, as well as actual customer electric usage. Market prices may fluctuate substantially over relatively short periods of time, potentially adversely affecting financial results of operations and cash flows. Changes in market prices for electricity and fuel may result from several factors.

RRM is intended to assist an Aggregator in the course of its day-to-day operations by allowing it to assess and compare actual electric usage of its customers against hedged positions viewed in aggregate. Market conditions (e.g., prices, congestion, outages, etc) and weather data are also available within RRM. The Aggregator may use RRM to configure alarms that trigger off of fluctuating market and/or customer usage conditions compared against standing retail contracts and hedged positions. Automatic alert of pre-configured conditions are sent to the Aggregator's Operations personnel as well as end-use customers. Recipients of alerts may then respond by adjusting hedges, schedules, and/or electricity usage. In this way, RRM alerts customers at times when actual or forecasted market and usage conditions dictate potential electricity cost savings taking into account the Aggregator's existing retail contracts and hedged positions. Furthermore, the system allows users to view estimates of the monetary impact of what-if adjustments assessed in the day-ahead. In such a way, RRM enables the demand-side (i.e., end-use customers through their Aggregators) to respond in the day-ahead as well as during the day-of. In essence, RRM is a market-driven demand response tool.

The document identifies what data is required, where it comes from, and how the data is related.

This document is included as Appendix $\mathrm{A}$ 


\subsubsection{Minimize the Cost of Data Collection}

Equipping an industrial plant or factory to collect and send information about the electrical usage of various pieces of equipment can require expensive material and take specialized labor to install and configure. In order to monitor the electrical usage at several plants this cost must be minimized. The traditional method was to install a computer with e-terracontrol software at a plant, provide an internet connection, and test. This would require someone who knows how to configure e-terracontrol to be on site for one or two days. The cost of the computer, software and labor could cost $\$ 30,000$ or more per plant. A new approach was necessary in order to facilitate adoption of this technology.

Instead of installing a computer at each plant, an intelligent meter connected to a terminal server that had access to the internet would provide measurements to the same computer that was collecting market data. An intelligent meter measures electricity and provides measurements via a DB-9 serial cable that is connected to a terminal server. The meter uses the Distributed Network Protocol (DNP) version 3.0 to communicate over the serial cable. A terminal server is a device that enables serial data to travel over the internet by wrapping it with the Internet Protocol (IP). A computer configured with e-terracontrol and connected to the internet removes this IP wrapper and the DNP data stream Is interpreted and the meter is read. The cost of the equipment is less than the cost of a computer and it does not require additional software. Additionally, this equipment is generally easier for a technician to install and configure compared with a computer running e-terracontrol. In the past we have encountered resistance from plant personnel to install new equipment. In order to minimize this resistance, detailed instructions were developed to make this installation as trouble free as possible. The estimated cost for this alternative installation is $\$ 10,000$ to $\$ 12,000$.

Experienced engineers documented detailed instructions to enable a technician to install a Bitronics intelligent meter (Bitronics model number MTWDE1B-S113). These instructions also included information to configure a terminal server to provide internet access to the Bitronics meter. A Comtrol Terminal server (Comtrol part number 3000202) was used for this test. The instructions were tested in the AREVA factory to verify accuracy and usability.

The Bitronics meter, Comtrol terminal server, and installation instructions were given to a technician to install in the AREVA factory. To simulate a field install, the technician was only allowed to use the provided equipment, standard tools, and the provided Digital Subscriber Line (DSL) internet connection. Additional information not in the documented installation and configuration guide could only be obtained using a standard telephone. After a few revisions, the instructions proved to be adequate to meet the requirements. After the installation was complete, the intelligent meter was read remotely over the internet using a computer with e-terracontrol installed on it. This computer had an internet connection and was to mimic a computer located in a data center. The data center computer read the remote meter and e-terracontrol monitored and recorded the measurements provided by the Bitronics meter.

These installation and configuration documents are included as Appendix B and Appendix C. 


\section{Functional Summary of the Advanced C\&C System}

\subsection{Functional Summary}

\subsubsection{Overview}

This section describes an information management system that provides Sempra Energy Solutions (SES) operations personnel "real-time" visibility to loads at target industrial and commercial (C\&I) sites and locational market prices for these sites. The target sites are three cement plants in New York, New Jersey, and Michigan, respectively, and are all owned by the same holding company. The proof-of-concept system is a real-time resource and market management system (RMS) developed by AREVA. The system is comprised of existing AREVA software components commonly used in wholesale electricity market and bulk power system management. The components include e-terra marketmanager, e-terracontrol, and e-terramarketwareUI. The components were brought together and tailored for demand-side application, as shown in Figure 3-1.

RMS provides real-time monitoring, automated alarming, and market prices in PJM and NYISO regions (and also MISO market prices when available). The system also monitors and stores information on actual plant electricity usage as well as alarm thresholds stemming from pertinent contract-based parameters. The system is composed of data acquisition gateways at target customer sites, IP-based data communications, and a Server with data management functions to be housed at SES's operations center in San Diego, CA. Metered plant data and market price information are accessed via a web-based user interface.

Figure 3-1 below provides an overview of this Proof of Concept demonstration system.

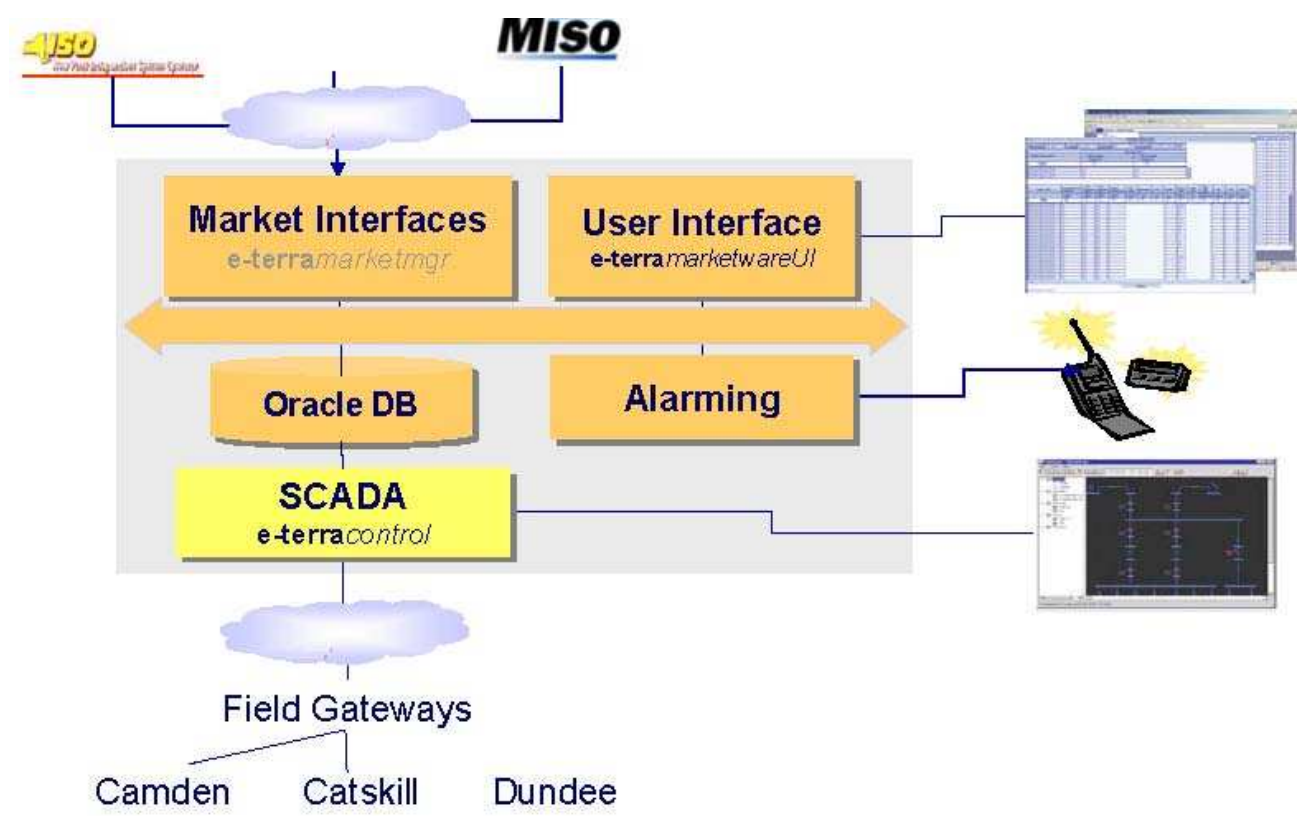

Figure 3-1: Proof of Concept System Overview 
RMS allows SES operations personnel and plant operators to respond to market signals such as PJM's real-time imbalance energy price, for which high prices typically coincide with peak demand periods. The system equips the user to alarm and notify SES and plant operators of opportunities to alter consumption or shed load based on real-time market conditions and actual electricity usage. As a result, RMS allows SES operations personnel to react more quickly, and ultimately provide a better service to its customers (e.g., by notifying customers in a fashion that would help minimize penalties paid for imbalance energy).

The RMS monitors, displays, and stores information including:

- Metered electricity usage

- ISO real-time and day-ahead energy market prices

- Price and usage thresholds (based on customer contracts)

- Contact information for personnel to be notified of alarms

Finally, RMS can be configured to perform real-time calculations on the monitored data and trigger alarms (by way of text messages sent to cell phones or email) upon reaching preconfigured alarm states.

Alarms trigger when price data from the ISO real-time energy market and metered usage for the current time indicate a potential and provide an incentive to decrease consumption. For example, alarms can be configured to trigger when actual usage exceeds contract-based thresholds, thus helping to mitigate potential negative effects on revenues due to penalties imposed when actual consumption exceeds contracted amounts.

RMS should assist SES in coordinating and communicating with customers to enhance their responsiveness during times when market conditions are favorable. By automating monitoring, alarming, and notification functions, the system overcomes the necessity for dedicated personnel to manually monitor market conditions and plant electricity usage. This is expected to decrease electricity costs during periods of high prices. 


\subsubsection{Plant Interface}

Two plant interfaces are available to be installed.

The figure below illustrates the plant interface implemented as part of proof-of-concept and individual components of the interface.

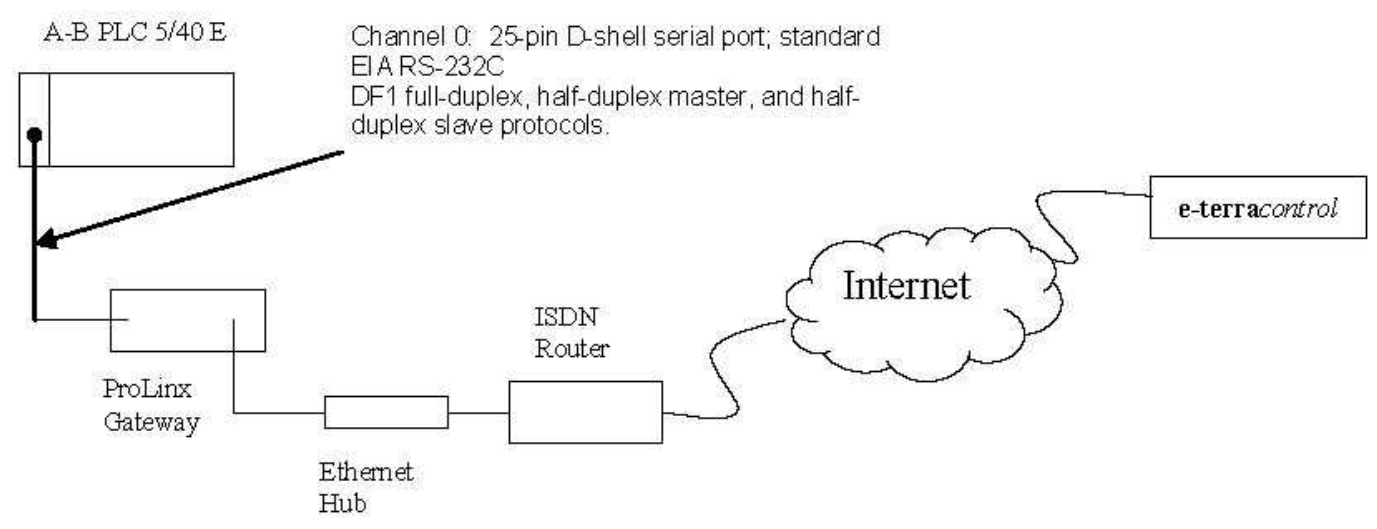

Figure 3-2a: Plant Interface Overview

The various components of the plant interface were configured as follows:

- ProLinx DF1 to Modbus TCP/IP Protocol converter connected to Allen Bradley PLC 5/40E over RS232 serial link

- ProLinx converter assigned static IP address and connected to Ethernet hub

- PLC memory mapped to Modbus registers inside ProLinx protocol converter

- Prolinx converter set up as Modbus slave

- AREVA e-terracontrol, acting as Modbus master which polls the ProLinx protocol converter to acquire PLC data

The figure below illustrates the plant interface tested in the AREVA factory and individual components of the interface. 


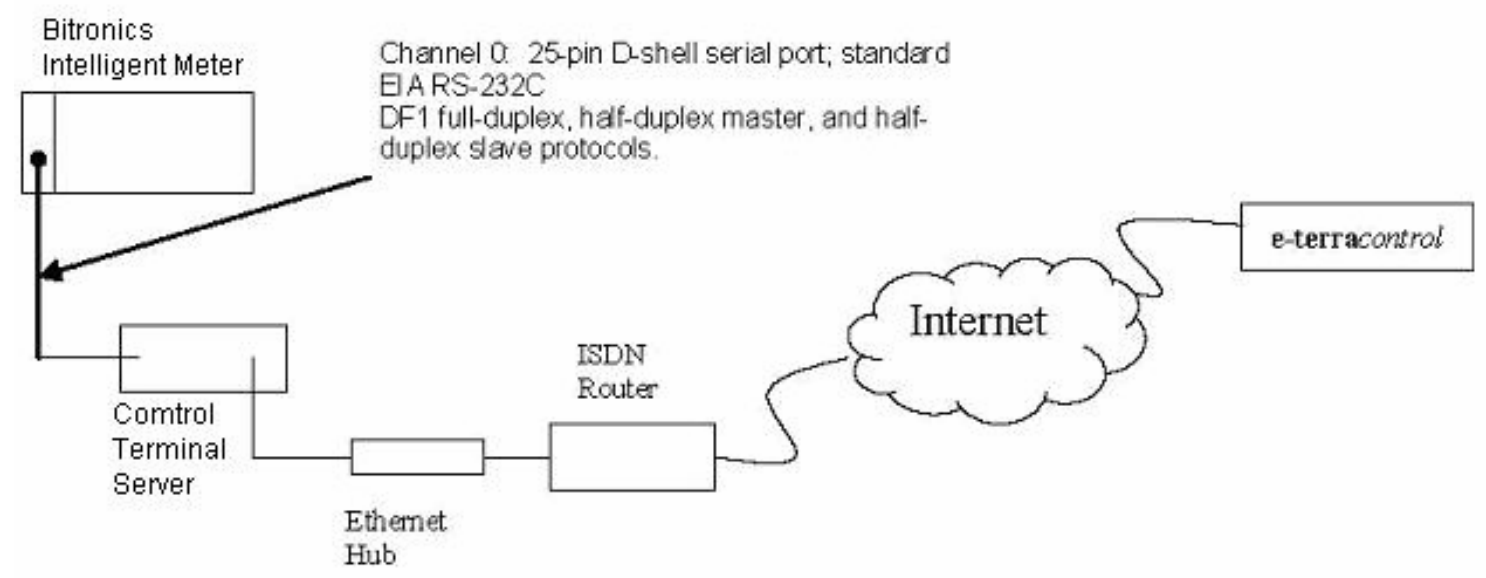

Figure 3-2b: Plant Interface Overview

The various components of the plant interface were configured as follows:

- Comtrol Terminal Server wraps serial DNP 3.0 into TCP/IP Protocol connected to Bitronics Intelligent meter over RS232 serial link

- Comtrol Terminal Server assigned static IP address and connected to Ethernet hub

- Bitronics Intelligent Meter provides electrical measurements using DNP 3.0 protocol.

- AREVA e-terracontrol, acting as DNP 3.0 master which polls the Bitronics Intelligent Meter to acquire measurements

\subsubsection{Assumptions}

The following assumptions were made in the implementation of the proof-of-concept demonstration system.

Assumptions concerning customer plants include:

- Plant usage data will be read at least every 5 minutes at each of the customer sites in Camden, NJ, Catskill, NY, and Dundee, MI.

- Always-on broadband Internet connections and static IP Addresses are available at each customer site being monitored.

Assumptions made concerning SES Operations Center include:

- Operations personnel that need to be notified have access to personal email and cell phones that can receive text messages.

- New users can be added and deleted, and user access permissions can by modified by SES.

Market assumptions include:

- Real-time market prices are published every 5 minutes by PJM, MISO, and NYISO.

- Established methods exist for which ISO prices can be accessed. 


\subsection{User Displays}

\subsubsection{Overview}

The RMS user interface (UI) allows SES personnel, along with plant operators and their managers to view market and usage data from the web. Furthermore, SES Commodity Operations have access to screens that allow for system configuration and alarm setup.

The primary UI screens demonstrated are summarized below.

1. Real-time Display - provides automatic updates of latest market price and metered electricity usage data, along with trending information indicating if values are rising or falling.

2. Alarm Configuration - allows SES to define conditions by which personnel will be notified or alarmed.

3. Contacts - allows input of contact name, email and cell phone that text messages will be sent to for alarming purposes. A distinct collection of contact name, email and cell phone information is associated with each alarm condition.

4. Market Price - a set of displays providing a tabular view of historical real-time LMP and day-ahead LMP data.

5. Plant View - screen that provides a tabular view of metered electricity usage data (MW) for select plants during the time period specified on that screen.

6. User Access Administration - Set of screens that allow users to be created and access level permissions to be set per user. Also user groups, individual users, and objects (i.e., screens) can be defined and managed.

\subsubsection{Real-time Display}

The Real-time Dashboard can be accessed via the following menu hierarchy.

\begin{tabular}{|c|c|}
\hline RT Dashboard Prices Usage Preferences Administration \\
\hline seal Time Display \\
\hline
\end{tabular}

Figure 3-3: Accessing a Display from Menu Options

\begin{tabular}{|c|c|c|c|c|c|c|c|}
\hline \multicolumn{7}{|c|}{ E'Realime Dasfiboard - Miorosoft Internet Explorer } & $-\square x$ \\
\hline No & Row Description & Regional Operator & Zone & \begin{tabular}{|l|} 
Price Date/Time \\
\end{tabular} & Last Price & Usage Date/Time & Last Usage \\
\hline 1 & Camden & PJM & PSEG & $01 / 15 / 200415: 02$ & $40.90 \quad$ & $01 / 15 / 200411: 21$ & 1.72 \\
\hline 2 & Plant in PPL & PJM & PPL & $01 / 15 / 200415: 02$ & $20.60+1$ & & - \\
\hline 3 & Catskill & NYISO & G - HUD VL & $01 / 15 / 200415: 10$ & $58.13 \psi$ & & $=$ \\
\hline
\end{tabular}

Figure 3-4: Real-time Dashboard Display

The Real-time Dashboard provides a tabular view of real-time price and usage values at selected plants and zones in regional markets pre-configured in the Real-time Display Configuration screen. The user can show multiple price zones or plants along with a text 
description associated with the values being displayed on the dashboard. The user may also choose to display the following values per plant or zone.

- Last Market Price

- Last Metered Usage

Latest values of selected information are displayed and any changes automatically updated. Arrows and dash marks indicate the trend between the current values displayed compared to the previous ones. A dash mark indicates that the current value is unchanged from the previous. Rising prices are indicated by red arrows, signifying an adverse situation for net buyers of electricity, such as energy retailers and end-use customers.

\subsubsection{Alarming}

Alarm conditions can be configured in RMS to alarm, notify, and provide load shed alerts to operators. SES has identified five types of alarm conditions that RMS supports, which are described below.

- Condition Type 1 is a price alarm that alerts when real-time price exceeds a high threshold value.

- Condition Type 2 is a price notification that alerts when real-time price exceeds a mid threshold value.

- Condition Type 3 is a site alarm that alerts to when market and usage conditions are such that the real-time price exceeds a mid- threshold value and actual usage exceeds the specified usage threshold value.

- Condition Type 4 is a site notification that alerts when market and usage conditions are such that the real-time price exceeds a low threshold value and actual usage exceeds the specified usage threshold value.

- Condition Type 5 is a site load shed alert and is triggered when market and usage conditions are such that the real-time price exceeds a high threshold value and actual usage exceeds the specified usage threshold value.

Specified personnel will receive alarms in the form of text messages when alarm, notification, or load shed alert states are reached. Currently text messages can be sent to email addresses or cell phones that support text messaging.

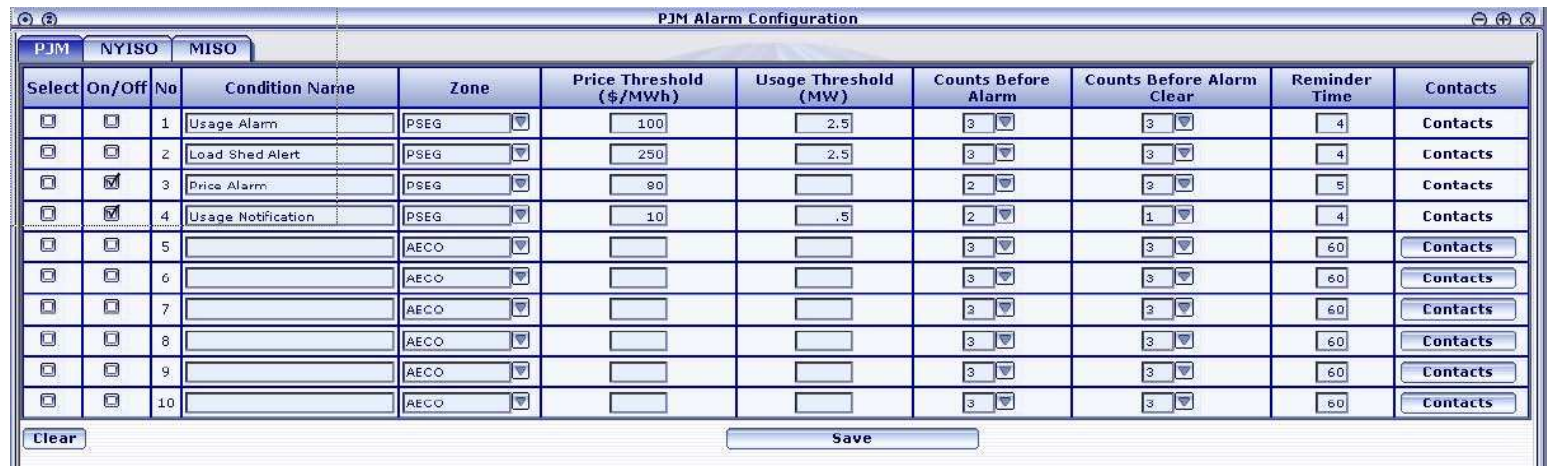

Figure 3-5: Alarm Configuration Display 
The user configures alarm conditions using the above display. Besides specifying the regional market, zone, and name for each condition, the user enters price and usage thresholds defining the alarm condition. Through pull down menus, the user specifies the number of times a price or usage threshold is exceeded before an alarm is generated or cleared. In addition, the user can specify the duration after the first alarm event before another alarm is sent as a reminder. An entry of 12 for Reminder Time is equivalent to a wait duration of one hour.

\subsubsection{Contacts}

The Contacts display shown below is accessed from the Alarm Configuration screen.

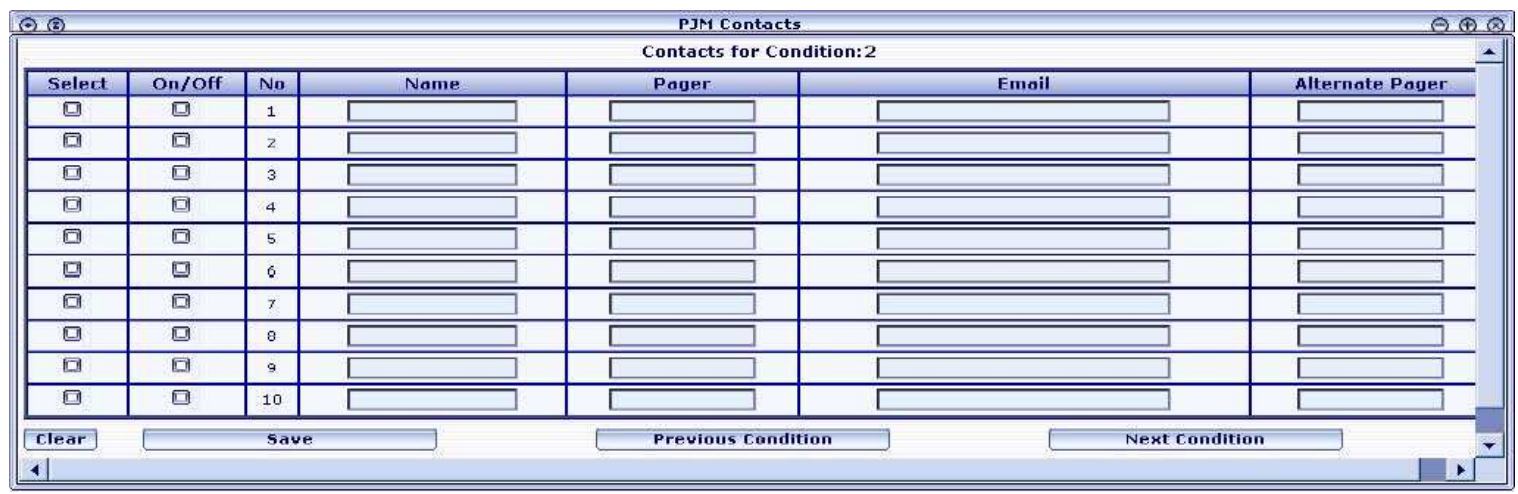

Figure 3-6: Contact Information Display

The user specifies the following parameters per contact person:

- Name

- Pager number

- Email address

- Alternate Pager

Multiple contacts can be specified per alarm condition. The user selects the on/off check box to alarm the contact person defined on the corresponding row. If the radial button is not selected, then the corresponding contact person will not be alarmed when the associated alarm condition is satisfied. Contact information can also be deleted, modified, and saved from this screen. 


\subsubsection{Market Price and Metered Usage Details}

Historical data can be accessed via tabular displays.

The market price tabular display allows the user to query downloaded market price data for a user-selected regional market and date range. By clicking on the "Export to CSV" button on the bottom of the display, the user can save the results to a file in .csv format for subsequent data handling using Excel.

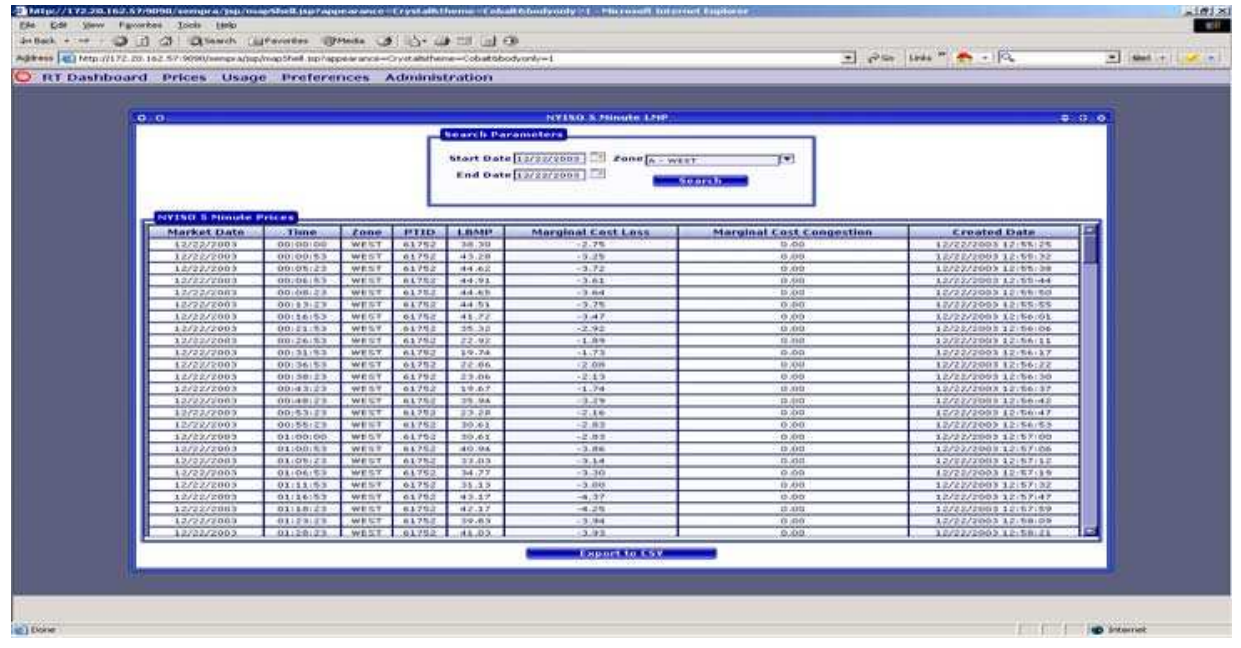

Figure 3-7: Market Price Details

The tabular display below allows the user to query metered usage data for a user-selected date range and plant within a chosen zone. By clicking on the "Export to CSV" button on the bottom of the display, the user can save the results to a file in .csv format for subsequent data handling using Excel.

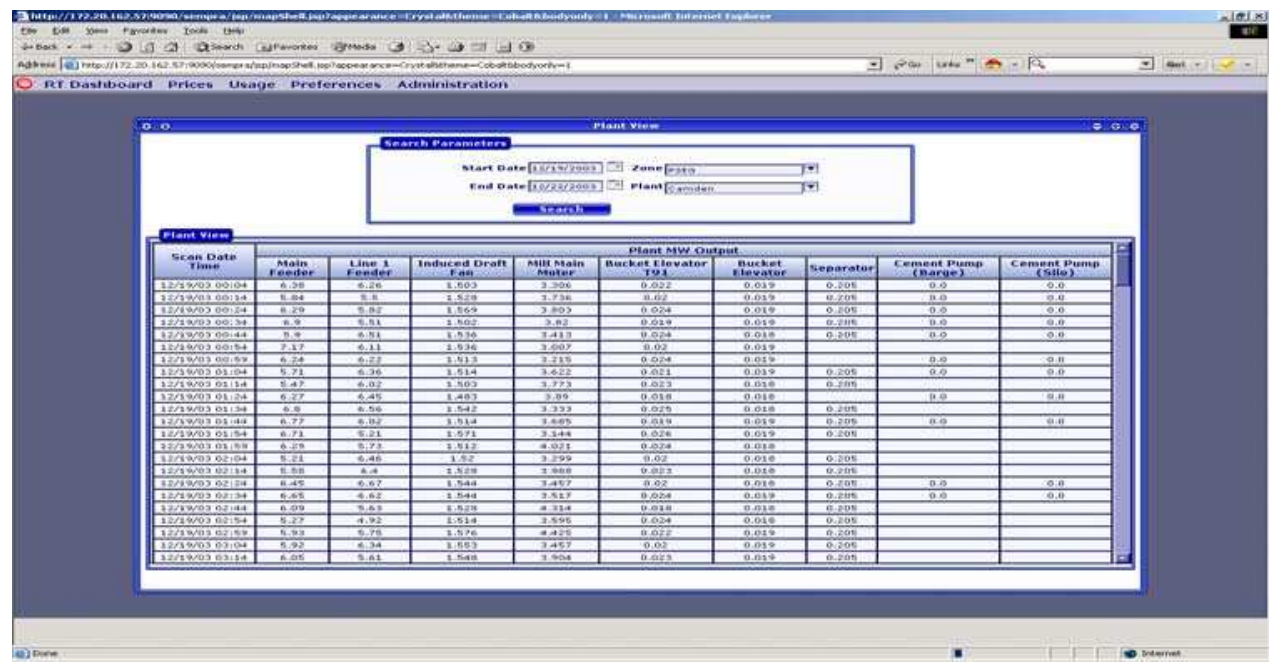

Figure 3-8: Plant Usage Details 


\subsubsection{User Access Administration}

A secure method is provided by which a user can log onto a Website to access RMS. Once the user enters a proper username and password, the user is in the clear to access any of the graphical displays it has rights to view, and is in the clear to specify preferences for parameters that it has rights to edit.

Currently, the POC system is setup so that any user in the Administrator group can change passwords and assign access privileges to other users. Users in the Commodity Operations group have view and edit privileges for all screens except the Administration screens. And users in the SES group have view-only privileges to the screens that the Commodity Operations group has access to.

\subsection{Experiences Gained}

Identifying how internet connectivity was to be provided to remote host facilities was more difficult than expected. Due to their remote locations, internet connectivity on a 24 by 7 basis is not feasible. Facilities without this connectivity are not able to take full advantage of the technology investigated in this project. Sempra was reluctant to install data collection equipment in additional plants during this project. Site installation involves multiple vendors and methods for broadband internet access installation. Consequently, lack of existing internet connectivity at customer sites posed the greatest potential delay and uncertainty to meeting project schedule.

Among lessons learned are the importance of obtaining full customer backing and support for gaining proper information on connectivity and network access. Towards this it was important to communicate to the customer early on the benefits they can expect from project involvement.

Another issue encountered was the higher tendency to lose connectivity with metered demand-side resources compared to generation and transmission assets normally monitored using SCADA technology such as AREVA's e-terracontrol. Lost of connectivity to a plant was detected when timestamps varied from the current time, as shown in Figure 3-9. Slow response times by industrial plant personnel compared to dedicated utility personnel in addressing cabling and other possible SCADA connectivity issues substantially delayed resolution of plant connectivity problems. Occasional unexpected plant shutdowns due to weather conditions cast further doubt on the accuracy of monitored usage values. The experience gained in monitoring end-use loads included a greater uncertainty and potential variability surrounding actual customer usage on any given day. The variability is due to a variety of factors (e.g., onsite cabling or internet connection issues) that can affect connectivity to customers as well as factors (e.g., weather or business conditions) that can affect actual electricity consumption.

\begin{tabular}{|c|c|c|c|c|c|c|c|}
\hline \multicolumn{7}{|c|}{ gl Reairime Dashboard-Microsoft internet Explorer } & \multirow{2}{*}{$-\mid$ 미 $x$} \\
\hline No & Row Description & Regional Operator & Zone & Price Date/Time & Last Price & Usage Date/Time & \\
\hline 1 & Camden & PJM & PSEG & $01 / 28 / 200418: 32$ & $165.00 \uparrow$ & $01 / 24 / 200408: 39$ & 0.99 \\
\hline
\end{tabular}

Figure 3-9: Example of an Instance of Lost Plant Connectivity 


\subsection{Conclusions}

The AREVA project was premised on the ease of building upon existing SCADA and market interface tools used by wholesale market participants and adapting the tools for retail demand-side applications. The approach proved to be optimistic and the effort to enhance the legacy C\&C system to maintain Sempra's interest in this project was under-estimated. The project had to adapt to a dynamic environment. The proof of concept system developed during phase one could not be enhanced to the degree that would maintain Sempra's interest to continue their participation. The project investigated several ideas to build or enhance a system to hold our subcontractor's interest, each turned out to be either infeasible or not interesting to the subcontractor. Once it was determined, the legacy system would not meet the functional requirements of the customer as it was and it was clear that there wasn't enough budget to build one that would, the project hit an implementation roadblock. Upon investigating other approaches to flatten the load curve, each investigation proved to require significant capital investments with challenging pay back periods.

This report recommends that a follow-on project study how price will modify consumption patterns of electrical energy. Without a competitive pricing structure for electricity during peak load periods, availability of adequate electrical energy during peak load conditions will become uncertain. The price of electricity that will modify consumption for different commercial load types has yet to be determined in several markets. A well-designed electrical pricing model will decrease load diversity. Reduced load diversity may provide capacity without construction of additional resources. This is a short-term benefit assuming energy consumption is not modified by shifting utilization.

Each commercial sector has a different demand characteristic. In the future, various commercial sectors will vie for the limited electrical energy available during peak load periods. The commercial sectors that will successfully operate during peak load periods will procure this resource by a combination of energy shifting and saving techniques.

Currently the difference in the marginal cost of electricity during a maximum load compared with a minimum load does not appear to be great enough warrant these measures. 


\section{APPENDIX A - Sempra Energy Services Desired Functions of a Market-Driven Retail Energy Risk Management System}

November 20, 2004 


\section{TABLE OF CONTENTS}

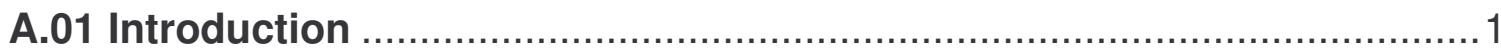

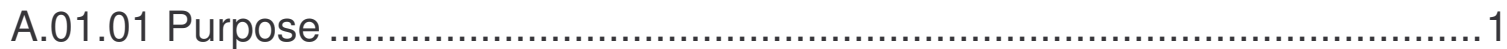

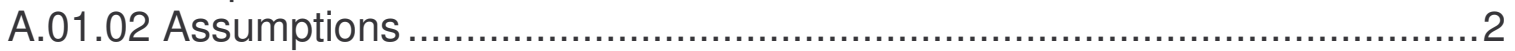

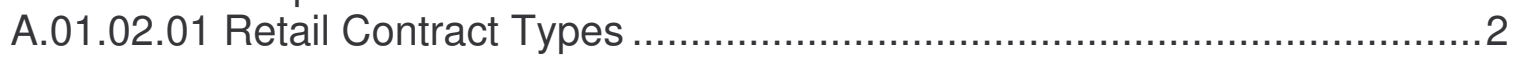

A.02 General Functions

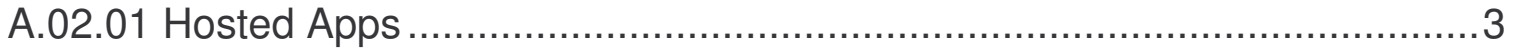

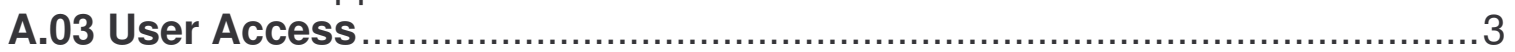

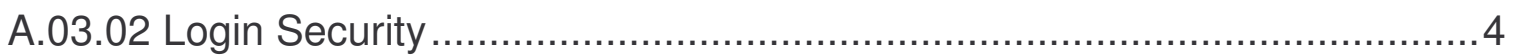

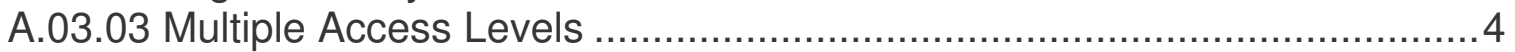

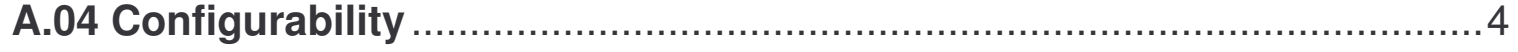

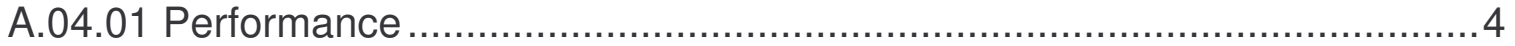

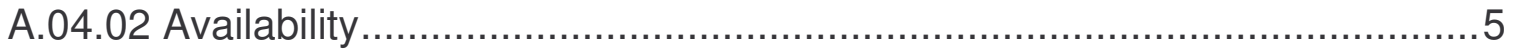

A.04.03 Historical Archive of Real-time Usage ............................................

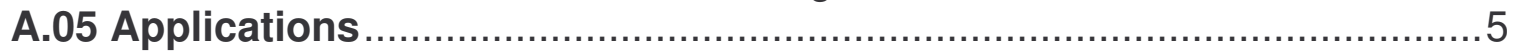

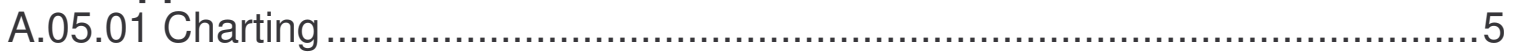

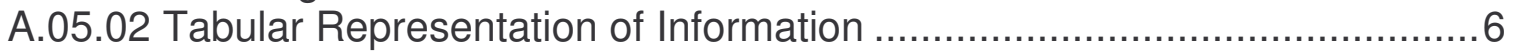

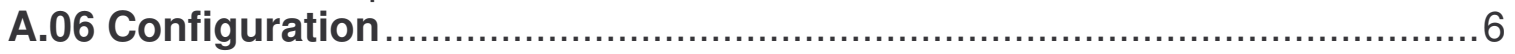

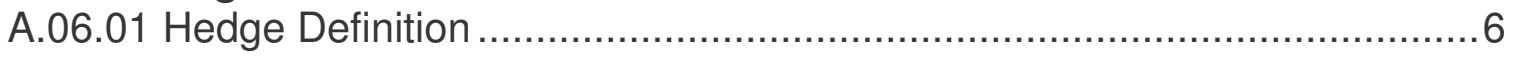

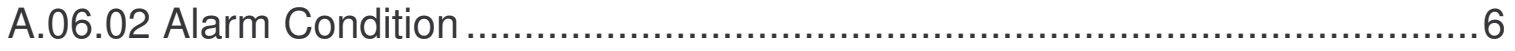

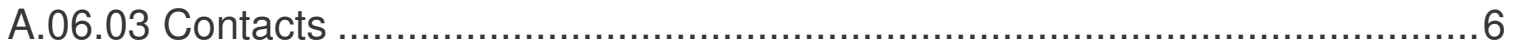

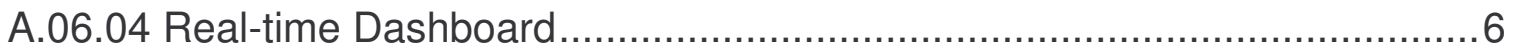

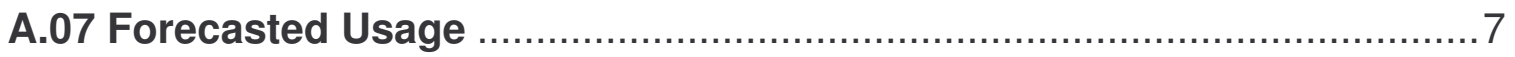

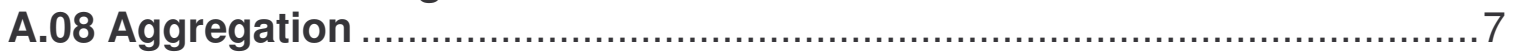

A.09 Figure 1: Calendar for Selection of Day/Profile ............................... 8

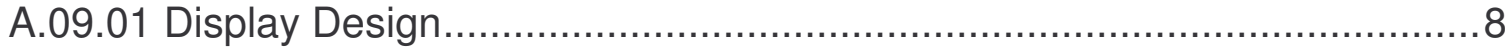

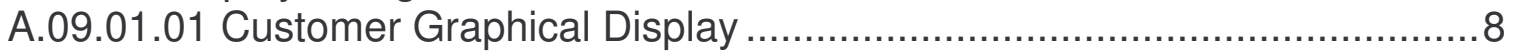

A.09.01.02 Figure 2: Graphical Chart for Customer ........................................ 8

A.09.01.02.01 Aggregator Graphical Display ..............................................

A.09.01.03 Figure 3: Graphical Chart for Aggregator........................................

A.09.01.03.01 Aggregator Position and P\&L Display (Optional) ........................

A.09.01.04 Figure 4: P\&L Display for Scheduler .............................................10

A.09.01.04.01 External Interfaces.........................................................10

A.09.01.04.02 Overview of Data-feeds Desired ...........................................10

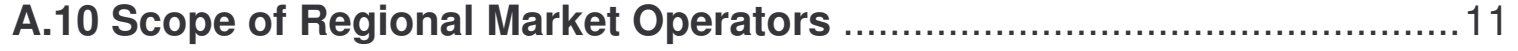

A.10.01 Participant Certification.......................................................... 11

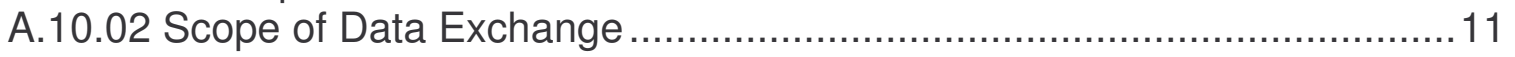

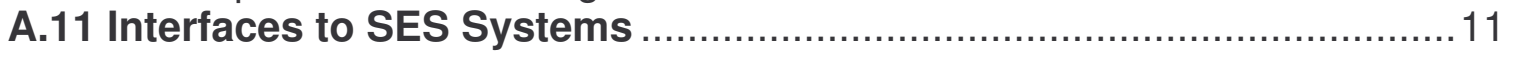

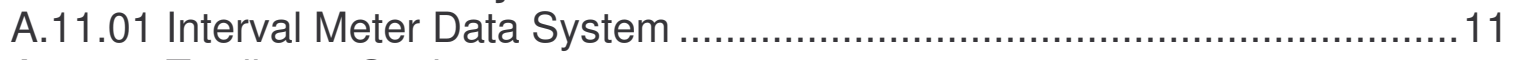

A.11.02 Trading \& Settlements ................................................................11

A.11.03 Customer Relationship Mgmt Systems..........................................11

A.12 Information Management System ............................................. 12

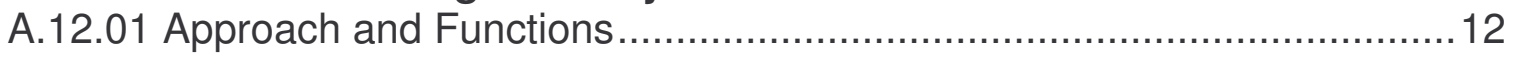

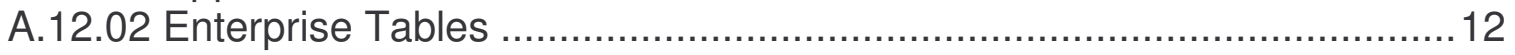




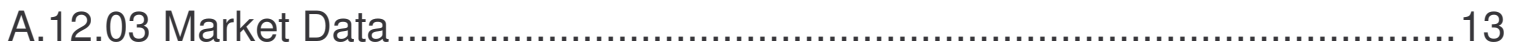

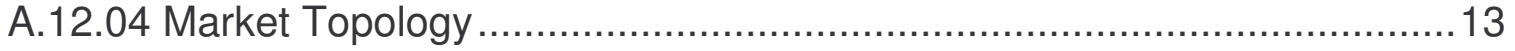

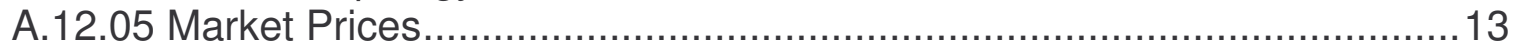

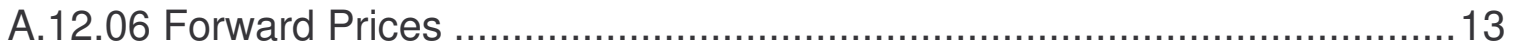

A.12.07 Load Forecast, Weather ....................................................... 14

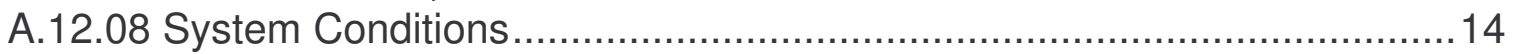

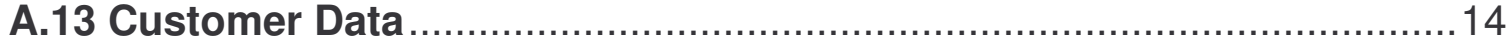

A.13.01 Customer / Facility ....................................................................

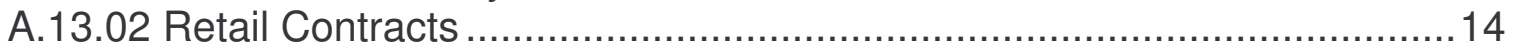

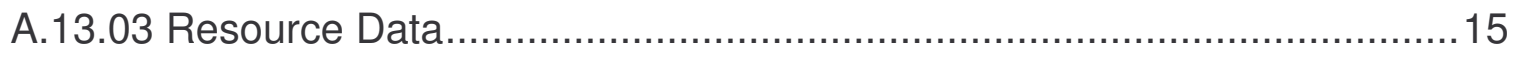

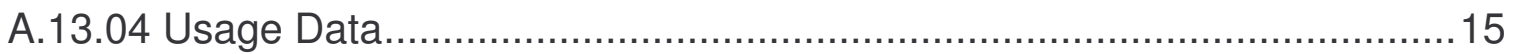

A.13.05 Aggregated Demand Forecasts .................................................15

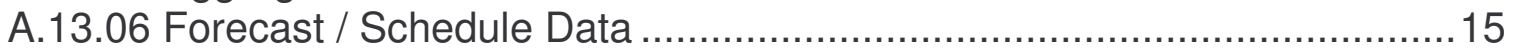

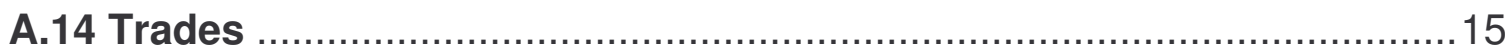

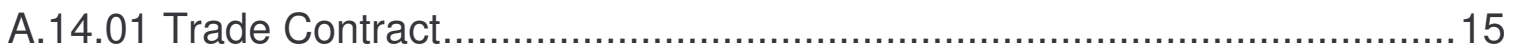

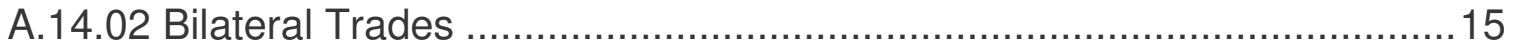

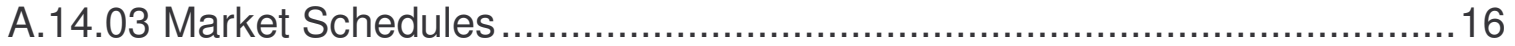

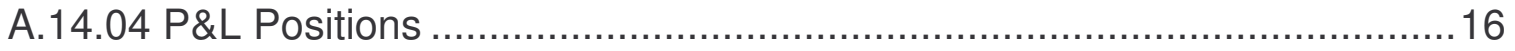

A.14.05 Settlements and Billing .................................................................

A.15 Appendix A - Data Structures and Summary Checklist ....................17

A.15.01 Customer Displays .................................................................17

A.16 Figure 5: Data Required for Customer Contract Tabular Display ........18 A.17 Figure 6: Data Required for Graphical and Tabular Displays of Rolling

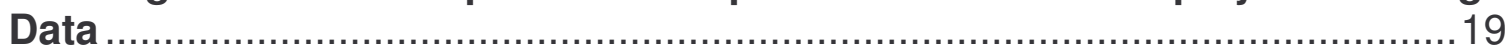

A.17.01 Aggregator Displays ............................................................19

A.18 Figure 7: Data Required for Aggregator Displays ............................20

Table 1: DATA PARAMETERS IDENTIFICATION TABLE ........................20

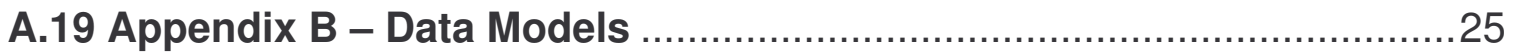

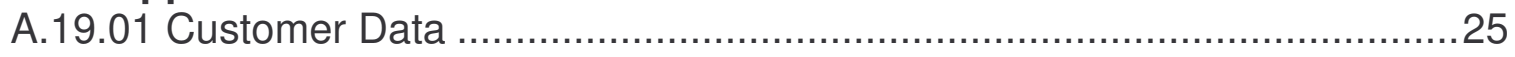

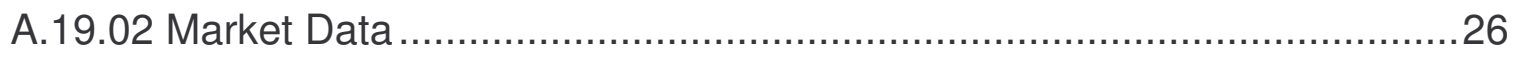

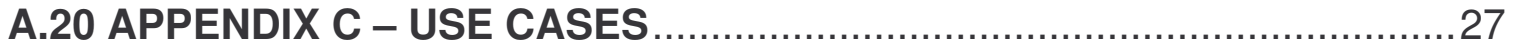

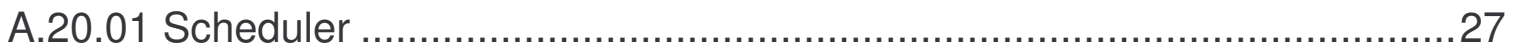

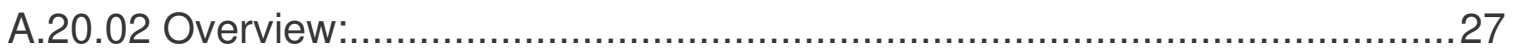

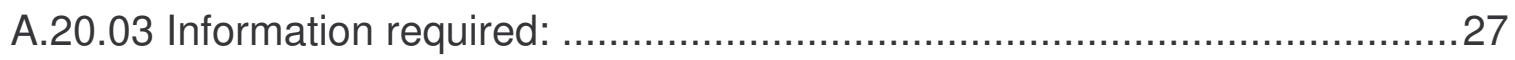

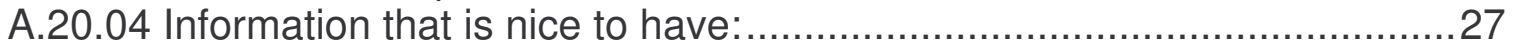

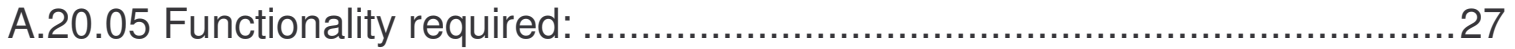

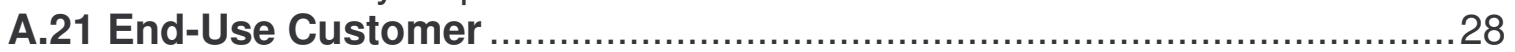

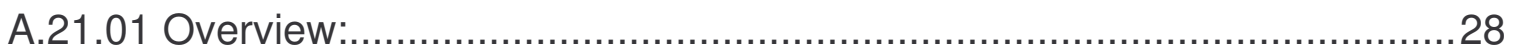

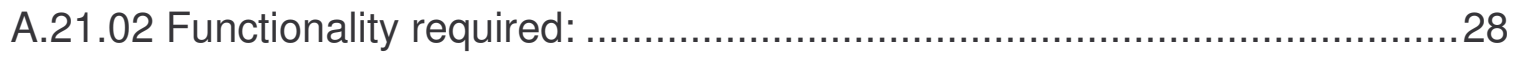

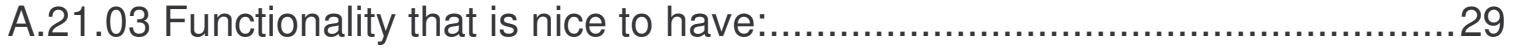

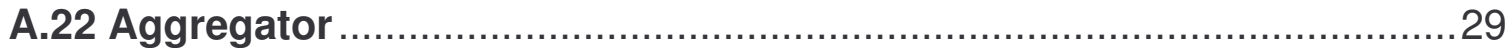

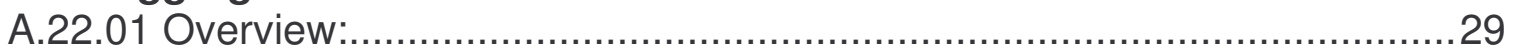

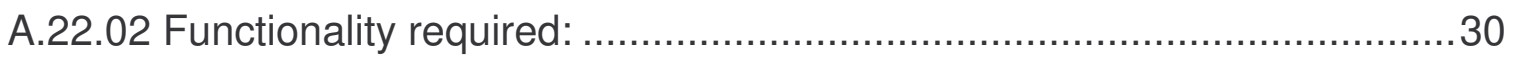

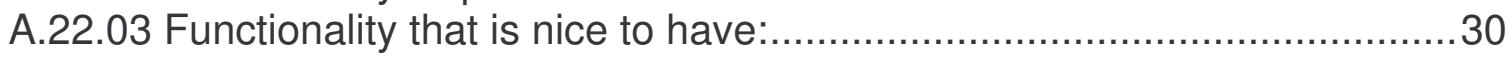




\section{A.01 Introduction}

\section{A.01.01 Purpose}

The purpose of this document is to describe the functions of a Retail Risk Management (RRM) system that an Energy Retailer serving as an Aggregator, can use to better serve the electric supply needs of large Commercial and Industrial customers. This document is not intended to construe a commitment of delivery of these functions. Instead, this document is intended to capture the desired functions for consideration when designing a future RRM.

The Retail Energy business is exposed to market risks that cannot be fully mitigated. They sell electric energy, capacity, and ancillary services and purchase fuel through short and long-term contracts or spot markets. Therefore the financial results from operations and cash flows depend on prevailing market prices for electricity and fuel markets, as well as actual customer electric usage. Market prices may fluctuate substantially over relatively short periods of time, potentially adversely affecting financial results of operations and cash flows. Changes in market prices for electricity and fuel may result from the following factors, among others:

- Weather conditions and seasonality

- Demand for energy and other commodities

- Forced or unscheduled plant outages

- Disruption of electricity transmission or gas transportation, infrastructure or other constraints and inefficiencies;

- Availability of competitively priced alternative energy sources

- Availability and levels of storage and inventory for fuel stocks

- Natural gas, crude oil and refined products, and coal production levels

RRM is intended to assist an Aggregator in the course of its day-to-day operations by allowing it to assess and compare actual electric usage of its customers against hedged positions viewed in aggregate. Market conditions (e.g., prices, congestion, outages, etc) and weather data are also available within RRM. The Aggregator may use RRM to configure alarms that trigger off of fluctuating market and/or customer usage conditions compared against standing retail contracts and hedged positions. Automatic alert of pre-configured conditions are sent to the Aggregator's Operations personnel as well as end-use customers. Recipients of alerts may then respond by adjusting hedges, schedules, and/or electricity usage. In this way, RRM alerts customers at times when actual or forecasted market and usage conditions dictate potential electricity cost savings taking into account the Aggregator's existing retail contracts and hedged positions. Furthermore, the system allows users to view estimates of the monetary impact of what-if adjustments assessed in the dayahead. In such a way, RRM enables the demand-side (i.e., end-use customers through their Aggregators) to respond in the day-ahead as well as during the 
day-of. In essence, RRM is a market-driven demand response tool.

\section{A.01.02 Assumptions}

\section{A.01.02.01 Retail Contract Types}

The types of retail contracts to be supported include:

- $\quad$ Fixed price, fixed volume: a nominated volume at a fixed price is specified, beyond which the customer pays the incremental price when they exceed the nominated volume and below which they are paid decremental price.

- Indexed: customer's whole price is based on a market price, for electricity or any other commodity.

- Index with Collar: a price range is specified within which the customer pays the index price, and limited by a cap (or ceiling) and a floor. The cap guarantees a maximum price, and the floor is the minimum price the customer pays even when the index falls below this threshold.

- $\quad$ Fractional Hedges: partly fixed price, partly indexed, and partly collared product.

Retail contracts specify whether the customer has a fixed contract volume or has chosen load following. For load following customers, the contract will specify additional parameters such as upper band and lower band or range of consumption or demand, and a method of forecasting load for scheduling purposes (e.g., schedule based on 1 or 2 year historical load or a forecasting model based on weather, production lines or other usage sensitive factors).

\section{A.01.02.02 Contract Parameters}

Key data elements per contracted customer account are:

- Forecast usage (MWh)

- Actual usage (MWh)

- Contracted retail price $(\$ / \mathrm{MWh})$

- Contracted volume (MWh)

- Forecast retail price (based on forecast usage $(\$ / \mathrm{MWh})$

- Estimated Actual retail price (based on actual usage (\$/MWh)

Some customers may be setup for real-time telemetry of electricity usage, which can be monitored by the Aggregator and/or customer. Customers' contract details specify whether customer is real-time metered and if so whether customer is also a Demand Response participant or willing to be involved in arbitrage (initiated by either by the Aggregator or customer). If so, customer contract 
details also specify customer ramp rates (i.e., how quick it can respond in $\mathrm{NW} / \mathrm{min}$ or MW/min) and other measures of the customers' ability to curtail load.

In addition, the retail contract specifies if the customer is exposed to passthrough charges, and if so identifies how charges are passed through to the customer. For example, for customers with fixed volume contracts, when the customer's usage deviates from contracted volume resulting in imbalance energy charges to the Aggregator, the charges are passed through to the customer, usually with some transaction fee.

Other retail contract details include customer's credit worthiness, contract type, capacity obligation, facility name and location, voltage level, customer class, start date, and term months. See Appendix A for a comprehensive list of customer contract parameters.

\section{A.02 General Functions}

\section{A.02.01 Hosted Apps}

Applications are accessed over the public Internet, with a designated site name reserved for accessing the hosted service. The system should support simultaneous access of at least 170 metered customers during the first year (or 30 end-use customers with up to 5 accounts each, plus 20 Operations personnel).

\section{A.03 User Access}

\section{A.03.01 Who is the User?}

The user is one of the staff the commodity operations group of the Aggregator. This may be a Transaction Structure, Portfolio Manager and/or Scheduler.

Assuming hedges are already placed for supplying end-use customer; the Portfolio Manager considers making adjustments to hedges given existing scheduling concerns. The Portfolio Manager aggregates all customers per portfolio (e.g., aggregated by ISO zone), and makes sure that total usage for the portfolio doesn't exceed what has been hedged in aggregate or makes adjustments to the portfolio to cover the expectations regarding updated or more accurate load and volume requirements.

The Scheduler makes adjustment to schedules day-ahead according to what he thinks will happen with the next day's load. Implementing telemetry to track usage of load following customers is of high value for the Scheduler. Regardless of how many customers within a zone are equipped with telemetry, forecasted usage in a zone improves when augmented by actual usage data for the aggregator's customer(s) in the zone. 
In order for the Aggregator to better serve its end-use customers, the AREVA system will also be accessible by end-use customers. The system will enable customers to respond to actual market conditions by allowing the Aggregator to configure alerts tailored to individual customer needs and their retail energy contract. For each customer that the Aggregator sets up in the system and configures to receive alerts, the system sends automatic alerts whenever monitored market and usage conditions hold true for the customer. The system also allows customers to view their actual \& forecasted usage (MW), actual and forecasted retail price $(\$ / \mathrm{MWh})$, and estimates of actual and forecasted electricity costs (\$). Furthermore, customers can input individual forecasted usage into the system, in order to provide the Aggregator with more accurate day-ahead usage forecasts.

\section{A.03.02 Login Security}

Individual user names and passwords will be required for system access over the public internet. Each user will have an expiration date associated with his/her user account and password.

\section{A.03.03 Multiple Access Levels}

User groups can be defined so that the same access level is shared by all users within a group. For example, users within the Administrator group may have access to all user access administration functions; the group of users within the Operator group may have access to all aggregation and customer alert functions; and users within the Customer group have access to view only their own data and have limited access to modifying their data.

\section{A.04 Configurability}

Must be able to configure and reconfigure on the fly:

- Algebraic equations and conditional statements through which to process data-streams (e.g., load and usage (MW, MWh), retail contract price (\$/MWh), volume (MWh), etc.)

- Market prices (\$/MWh)and usage conditions to be displayed on realtime dashboard

- Alert conditions to be monitored

- Personnel to be alerted

- Data-streams to view graphically

- Adjustments to contract parameters

- Data sources to use for forecasts (e.g., forecasted usage, forecasted prices, etc)

- Data sources for market information (e.g., location and method by which to download ISO data)

- User preferences (e.g., color scheme, graphical settings, etc)

\section{A.04.01 Performance}


Customer usage data connections should not be loss more than once per month (apart from connectivity issues of telecommunications provider beyond AREVA's control). The system should not require reboot exceeding once per month on average. Multiple alert conditions, on the order of thousands of monitored conditions, should be supported at any given time. The system should be scalable towards supporting hundreds of thousands of alert conditions upon launch of a commercial service.

\section{A.04.02 Availability}

Service support hours will be 7am-7pm for all time zones in the U.S., and customers chosen accordingly. However, SES would eventually like to have 24/7 service to accommodate all SES' customers.

\section{A.04.03 Historical Archive of Real-time Usage}

The system has value in providing usage data for the time gap in which meter data is not available. Typically meter day is only available from 30 to 90 days out. Therefore, historical usage data should be retained for at least 90 days back, after which any usage data older than 90 days can be archived. Archive retrieval should be easily and quickly accessed, and available for up to two years consumption history.

\section{A.05 Applications}

\section{A.05.01 Charting}

What to show to Customer in graphical form:

- Show historical chart with usage (MWh) over time.

- Show historical chart with retail contract prices over time (based on RT or DA LMP as options).

- Plot on the same chart: Actual usage, actual retail contract price in realtime

- Plot on the same chart: forecasted usage and forecasted retail contract price to customer given an assumed "usage forecast" selected by the customer from a menu of past daily usages

- How much getting charged underneath the hedge, how much getting charged when exceed their hedge

- Plot on the same chart: "what-if scenario" (based on adjusted usage and expected retail price like day-ahead retail contracted price)

Want to show to Operator:

- Show real-time, day-ahead, and hour ahead, balance of the week end, balance of month end, first of the month LMPs or averages thereof over a specified time window for selected ISO zones

- Plot aggregated usage and aggregated contract volume (MWh) as data comes in for all customers in portfolio. 
- Show weather feed (as an option).

- Show Index data (e.g., Dow Jones day-ahead on/off peak prices) as an option.

\section{A.05.02 Tabular Representation of Information}

- Show LMP prices over a specified time period (RT, DA, and historical options).

- Show aggregated and individually telemetered usage over a specified time period. (Usage data should be validated and apparent errors in telemetered values reconciled.)

- Show weather data over a specified time period.

\section{A.06 Configuration}

\section{A.06.01 Hedge Definition}

A Hedge and Retail Contract Condition Definition screen allows the Operator to define hedge conditions and retail contract price by inputting algebraic equations by which to process data-streams. Hedges can be constructed from contract parameters such as volume (MWh), price (\$/MWh), load (MW), and term (months). The Operator specifies data-streams and scalars, basic conditional expressions (i.e. $>,<,=, !,=$ ), and algebraic functions (i.e., $+,-,{ }^{*}, /$ ) and "if, then" statements to define hedge and contract conditions of interest.

\section{A.06.02 Alarm Condition}

An Alarm Condition Configuration screen allows the Operator to configure alert conditions and turn them on and off. Alerts can trigger off of actual retail or LMP price, weather, and/or usage data-streams when compared against preconfigured threshold values. Alerts may also be configured to trigger whenever pre-configured hedges are exceeded.

The Portfolio Manager monitors when aggregate usage for portfolio exceeds what has been hedged in aggregate by zone, and makes related adjustments, as appropriate.

\section{A.06.03 Contacts}

A Contact Configuration screen allows the Operator to specify personnel to be contacted (names, email address, pager number, etc) upon alerts being triggered.

\section{A.06.04 Real-time Dashboard}

A Real-time Dashboard Configuration screen allows the Operator to specify data- 
streams to display on a real-time continuous basis on the operator console. Datastreams that can be monitored in real-time include RT LMP, actual usage, and weather.

\section{A.07 Forecasted Usage}

The Scheduler wants to forecast in real-time using past data, since scheduling involves an active process of creating precision. Consequently, there is valueadd in having day-ahead and real-time tools that operate on usage data to improve the forecast day-ahead or day-of, and ultimately to create a better wholesale financial position.

A Usage Forecast Configuration screen allows the Operator to upload historical load for each customer ("to prime the pump") into the AREVA system, use algebraic equations or other modeling to define the forecast method, and subsequently allow customers to provide updates on its usage forecast.

\section{A.08 Aggregation}

The system allows the Operator to perform aggregation by ISO (price) zone or other criteria. Usage and contracted volumes are aggregated for all meters within a selected zone. Though the highest level of aggregation of interest is by zone, the system should also show aggregation at sublevels (e.g., aggregated values for all demand zones within the selected zone, facilities within the demand zones, meters within the facilities, sites or by customer).

Hourly usage is aggregated for a portfolio of customers (assuming customers in the portfolio are telemetered). Retail contract volumes are also aggregated for a portfolio of customers according to the Portfolio Manager's criteria. A portfolio is a grouping of contracts, or an aggregation of hedges from a wholesale standpoint, in order to fulfill or modify SES's volume requirements. The Portfolio Manager desires to aggregate volumes from retail contracts to compare against supply contracts procured. He/she decides the size and shape of the portfolio given the current situation (e.g., by ISO zone, type of volume block purchased, or certain wholesale supplier, but generally not by a customer grouping.

Consequently, the system also supports aggregation and sort of customer retail contracts by:

- Utility1

- Zone

- Node

- Portfolio

- Meter

- Premises or facility site

1 Though Operators that are Schedulers or Portfolio Managers want to primarily aggregate by ISO price zone, personnel from the Structuring group of the Aggregator may also want to aggregate by utility and customer (contract). 
- Customer (multi-site, multi-zone)

- Contract type

Optionally, the Operator is given the ability to grab and block peak, off-peak, and semi-peak volumes on selected days of interest (e.g., last 5 Fridays only). The dates can be blocked or point selected from a calendar box as below. As another option, customers may sample recorded past load shapes to apply to current real time pricing scenario, by selecting from a calendar depicting load profiles associated with each day (as below).

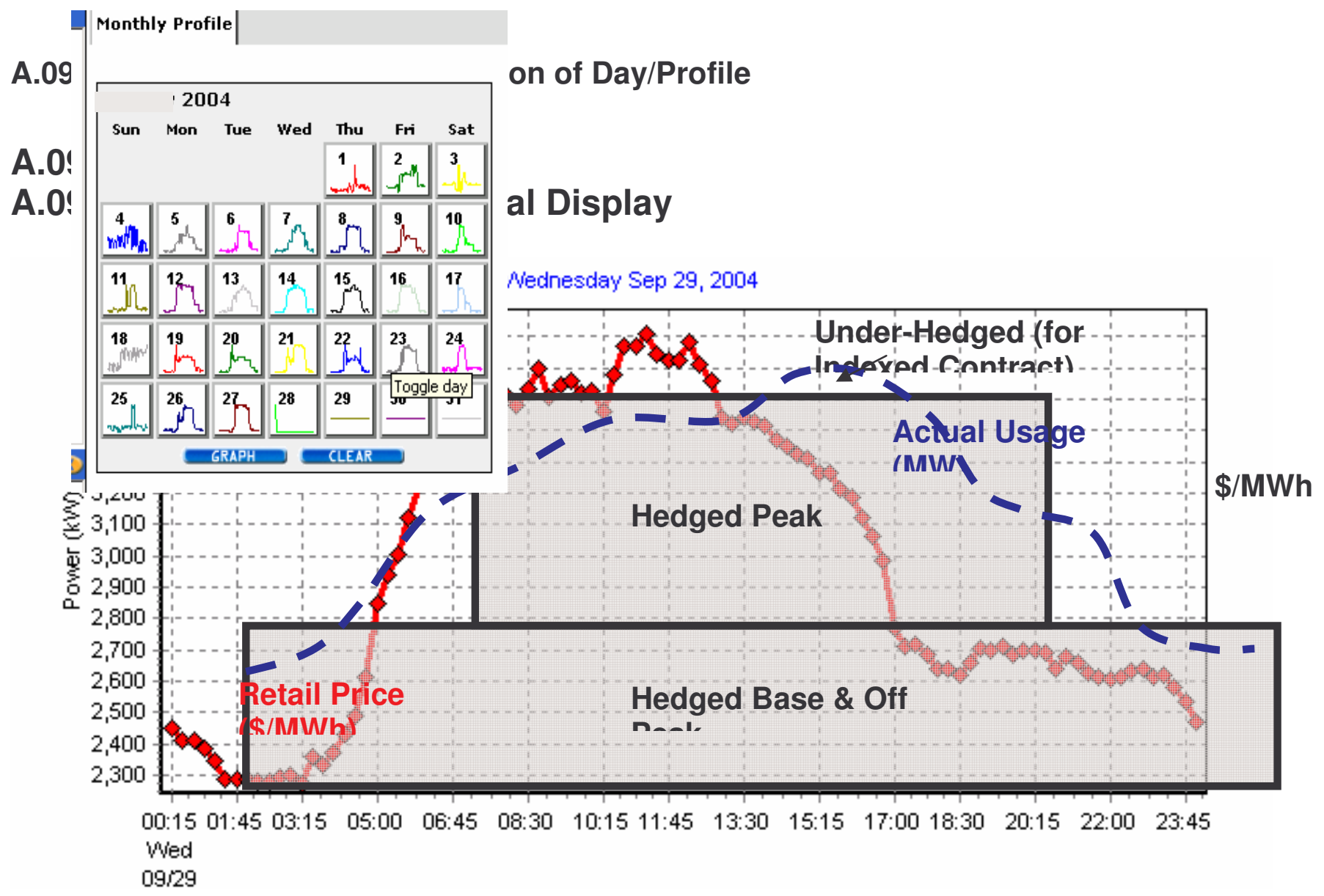

\section{A.09.01.02 Figure 2: Graphical Chart for Customer}

The customer will see multiple graphs representing its recorded Usage, retail Price, and estimated Cost (i.e., contracted Volume $x$ Retail Contract Price) with Hedged and Under-hedged values evident. Hedged blocks representing the customer's contracted volume (i.e., hedge) will be shaded in, as above. The latest values for Usage and Price will plot automatically on the graphical display.

For example, a customer with an indexed contract will see a graphical display such as above, with the retail price based on an Index such as the Imbalance 
market price. For customer with a fixed-price, fixed-volume contract, the retail Price at any given time depends on whether the customer is under-hedged or over-hedged. Whenever actual usage is covered by the hedge (i.e., contracted volume exceeds actual usage), the retail price is the fixed price. Whenever the actual usage exceeds contracted volume, the customer is under-hedged, and the retail Price is based on an index multiplied by an agreed upon transaction fee.

\section{A.09.01.02.01 Aggregator Graphical Display}

The Operator will see similar usage and volume information available on the Customer Graphical Display, but aggregated by zone. The Operator also sees the ISO imbalance market prices for a selected zone.

An Analysis option allows the Operator to specify algebraic computations, conditional statements, and desired weather feeds for developing and storing forecasting formulas.

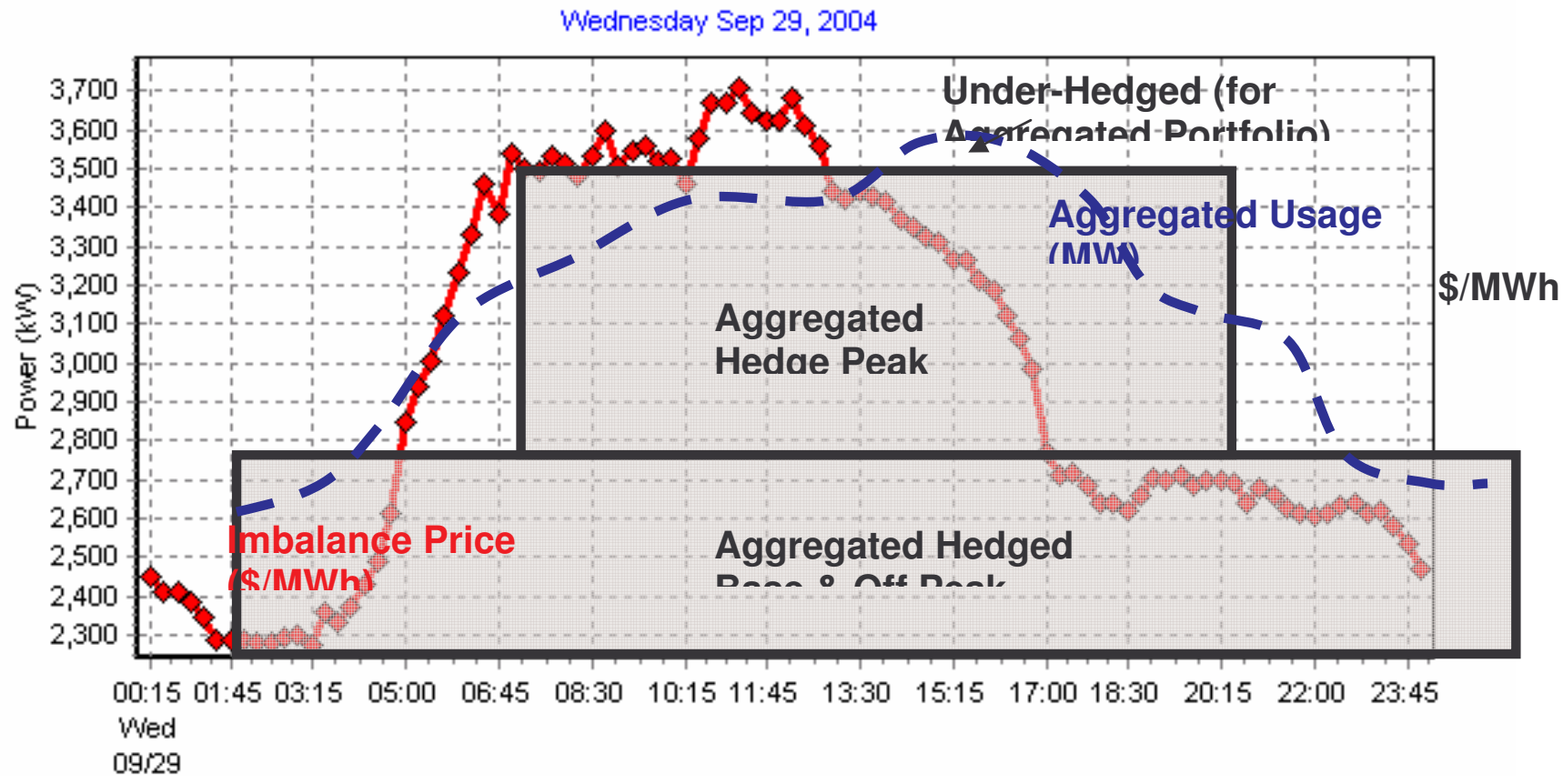

\section{A.09.01.03 Figure 3: Graphical Chart for Aggregator}

\section{A.09.01.03.01 Aggregator Position and P\&L Display (Optional)}

Forecasted demand is displayed along-side procured supply, to reveal net (wholesale) position in MW as well as in \$ Revenue. The Operator may graph the forecasted demand and (wholesale) supply positions for a selected zone, and determine his/her net position at any given time. Monitoring of wholesale 
positions for automatic alarming based on preconfigured conditions is also supported.

\section{A.09.01.04 Figure 4: P\&L Display for Scheduler}

\section{A.09.01.04.01 External Interfaces A.09.01.04.02 Overview of Data-feeds Desired}

The system allows the Operator to track the following data-feeds:

- CAISO: day-ahead and real-time prices for SP15 \& NP15, Palo Verde, COB (Calif. \& Oregon border);

- ERCOT: day-ahead and real-time prices for Houston, North, NE, West, and South zones.

- NYISO: day-ahead and real-time energy prices for zones WEST(A), GENESE(B), CENTRL(C), NORTH (D), MHK VL (E), CAPITL (F), HUD VL (G), MILLWD (H), DUNWOD (I), N.Y.C. (J), LONGIL (K), Hydro Quebec, NePool, Ontario Hydro, and PJM.

- PJM: day-ahead and real-time energy prices for zones: AECO, APS, BGE, DPL, JCPL, METED, PECO, PENELEC, PEPCO, PJM, PPL, PSEG, RECO, WESTERN HUB.

- Midwest ISO: day-ahead and real-time energy prices for Cinergy. (or hold until MISO publishes RT prices)

- Transmission capacities from each of the ISO's are desired for Transmission and Schedule coordination.

- Generator availability (on/offline report) from ISO's. Also Hydro report.

- ISO-published hour-ahead energy prices for CAISO and ERCOT, respectively. - (from where - ICE, DJ?)

- Also balance of the month and first of the month prices \& volumes for each of the ISO regions above (available by subscription).

- Heat rate from Houston Ship Channel in ERCOT (gas index available from NYMEX)

- Dow Jones Index (for day-ahead on-peak and off-peak prices)

- Mid Columbia electric index in Oregon (for both firm and non-firm) originating from Dow Jones news feed service

- Gas price index (available from NYMEX by subscription).

- Forward price curves (more than 1 month out as required by Portfolio Manager)

- Weather feed for temperature (in degree days)

SES currently receives by subscription service many of the non-ISO data-feeds identified in the bulleted list above. SES will determine which of the data-feeds above that it subscribes to can be fed into the AREVA system. 


\section{A.10 Scope of Regional Market Operators}

\section{A.10.01 Participant Certification}

The preferred approach is to download market data from regional market operators via standard XML interface whenever certification is required. In the few cases where regional operators provide public data download of .CSV files (compatible with standard spreadsheet software), the preferred approach is to download the database files. System design should also address security issues associated with handling of certificates (e.g., avoidance of accidental submission of schedules from a "certified" system).

\section{A.10.02 Scope of Data Exchange}

The initial markets of interest from which to download data for customers to view are ERCOT and PJM, and eventually CAISO.

The system downloads real-time LMPs, day-ahead LMPs, (and hour-ahead prices where available) by regional market, commodity type, and zone/node. Day-ahead forecasts published by regional market operators on transmission capacities, generator availability, and load are downloaded as available.

\section{A.11 Interfaces to SES Systems}

\section{A.11.01 Interval Meter Data System}

Historical hourly load data on metered or profiled customer usage is passed to AREVA systems from SES' historical load repository (Lodestar). Hourly historical load data must be transferred into the AREVA system to support computations on the data, graphical display, and alarming of the data.

\section{A.11.02 Trading \& Settlements}

Information on actual customer usage and market conditions (e.g., actual market prices, forecasts, schedules, awards, and outages) is passed from AREVA systems to SES systems. Financial valuation of actual and what-if scenario positions that are tracked within AREVA systems may be transferred to SES systems. As an option, information on wholesale positions is passed from SES's system (Allegro) to AREVA systems, in order to utilize the graphing, forecasting, automatic monitoring and alerting capabilities available within the system.

Data exchange between SES Trading \& Settlements systems and AREVA systems will occur through transfer of Excel or .CSV data files.

\section{A.11.03 Customer Relationship Mgmt Systems}

Customer contract parameters (e.g., load, volume, price, term, etc.) are passed to AREVA systems.

Data exchange between SES Customer Account systems and AREVA systems will occur through transfer of Excel or .CSV data files and/or manual data entry 
through a user interface.

\section{A.12 Information Management System}

\section{A.12.01 Approach and Functions}

The system shall support the following types of data:

- Dynamic Data - scanned or computed, on a periodic basis. Each data is associated with a time tag indicating the scan/computation time. Dynamic Data may be organized by

- Real-time $(R / T)$ values - the latest values associated with a given item. Real-Time data may be retained in memory

- Current Trend $(\mathrm{C} / \mathrm{T})$ - This is a recent trend/history of the data (e.g., past one week, or past one month). This data will be maintained in a fashion that can be quickly accessed by user interface.

- Historical Archive (HIS) - Long-term history. It may require special action to retrieve the historical data. The size of HIS should not impact the performance of $\mathrm{R} / \mathrm{T}$ and $\mathrm{C} / \mathrm{T}$ data access

- Static (standing) Data - These are data describing contracts, parameters and other values that do not periodically change. Static data will have creation and update times associated with them.

\section{A.12.02 Enterprise Tables}

These tables define markets, regions, companies, counterparties, customers, and users and their relationships.

The tables detail the attributes describing the "enterprise", including markets covered, company information, counterparty information, including name and address, as well as contact and credit limit information. Similar data is defined for customers. Customers may be linked with markets and regions.

Markets:

Company:

Market Name, Description, Products, Settlement Types

Company Name, Short name, Type, Duns No., NERC ID, Company Address, Billing Address, Parent Company Name, Contact Person, email, Credit Limit, Credit Status, Credit value

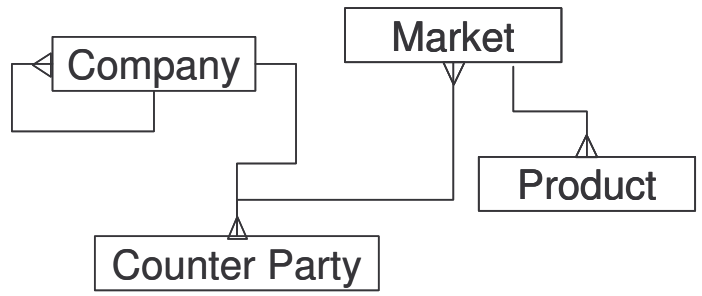
Counter Party: 
Company Name, Trading Function, Markets, Contact Name, Phone Number, Cell Phone Number, Pager Number, Fax Number, E-mail, Address, Time Zone, Credit :Limit, Credit Status, Credit Value, Product:

Name, Commodity, Time Interval, Units, Settlement Type, Interval, Spatial ....

\section{A.12.03 Market Data}

These include various tables needed to manage the data that are being downloaded from supported markets. Please note that market data may be managed in accordance to R/T, C/T and HIS organization. Also, note that the system will be managing data for multiple markets and the data structures should support this.

\section{A.12.04 Market Topology}

These tables define locations (e.g., zones, nodes, etc. and other topological data needed to manage the market information.

Utility: is a company (type)

Control Area: Name, Utility, Market

Zone: Name, Market, Control Area, Type, Hub, Time

Zone

Node: Name, Zone, type

Hub: Name, Market

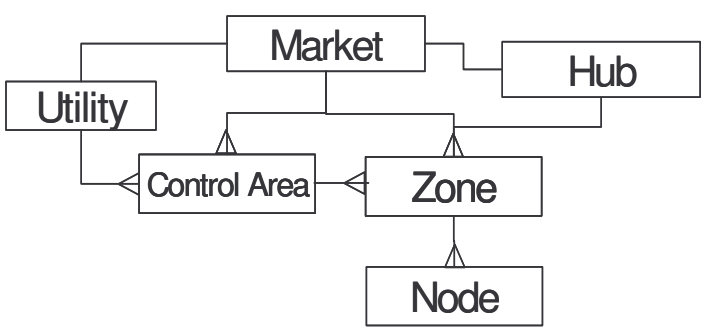

\section{A.12.05 Market Prices}

These tables maintain clearing prices for the market commodities and the markets that are supported. Included will be energy, ancillary services and FTR prices. These will be based on nodal representation.

Hourly (or sub hourly) Price: Market, Product, Zone, Node, Date, Time Interval (Hour, or subHr), Clearing Cycle (DA, HA, RT), Price, Units, Data Source, Time Stamp

Daily Price: Market, product, Zone, Node, Date, Price, Units, Data Source, Time Stamp

\section{A.12.06 Forward Prices}

Forward price curves by Hub, region and market, product. Forward prices may have the same structure as market prices.

Forward Price: Market, Hub, Product, Day, Time Interval (hour or Sub-hour), 
Price, Units, Source, and Time Stamp

\section{A.12.07 Load Forecast, Weather}

Load forecasts by market location/region. We should allow for both short term and medium term forecasts.

Forecast: Type, Market, Hub, Zone, Node, Day, Time Interval, Value, Units, Timestamp

Forecast Type: Name, description, Source

Weather: Source, Zone, Node, Day, Hour, Temp, Wind, Humidity, Dew Point, Time Stamp

\section{A.12.08 System Conditions}

Transmission loading and generation conditions forecasts published by market

\section{A.13 Customer Data}

\section{A.13.01 Customer / Facility}

Customer is a company

Facility (Plant): Name, Company, Address, Market, Zone, Node, Type, MW

Demand, Description

Facility Type: Name, Description

\section{A.13.02 Retail Contracts}

Retail customer contract parameters, including terms, markets, products covered, resources covered, operating parameters, costs, tariff, etc.

Retail Contract will contain the following information: Type, Counterparty, Start Date, Termination Date, Execution Date, Facility, Resource, Demand Profile, Nominated MW Value, Index Parameter, Cap, floor, Hedge \%.

Contract Type: Name, Description

Demand Profile: Customer, Facility, Name, Commodity,

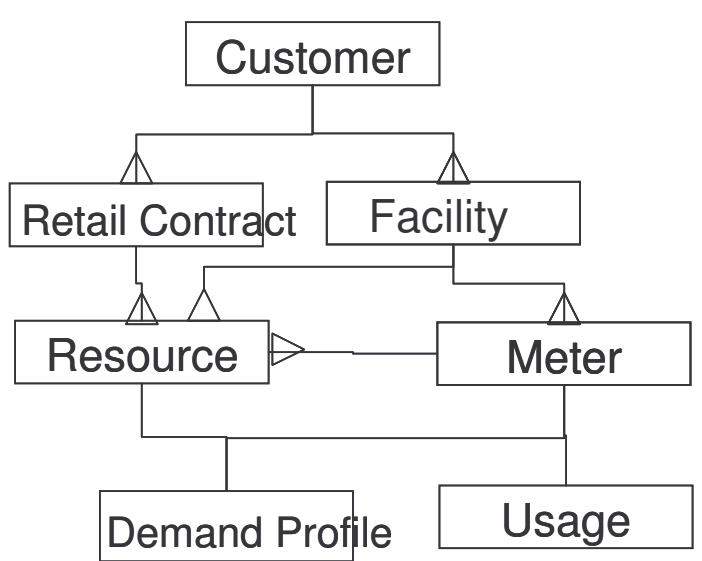
Type, Hour, Value, Unit 


\section{A.13.03 Resource Data}

Definition of resource parameters. Resource types and standard models for those resources will be defined. Associated parameters include

Demand Resource: ID, Name, Company, Facility, Type, Demand Level, Curtailment capability, Increments (parameters for curtailment), Meter ID Resource Type: Type, Description Resource Status: Resource ID, Status

Meter: Meter ID, Type, Facility

\section{A.13.04 Usage Data}

Metering data by resource and customer. R/T, C/T and HIS data should be supported.

Usage Data: Resource ID, Meter ID, Date, Time Interval, Value, Unit, Time Stamp

\section{A.13.05 Aggregated Demand Forecasts}

Aggregated demand data by customer, contract, region, etc. Aggregated Demand: ID, Name, Date, Time Interval, Value, Units Aggregated meters, ID, Meter IDs, Description

\section{A.13.06 Forecast / Schedule Data}

Demand Forecast: ID, Customer, Facility, Type, Day, Time Interval, Value, Units, Source, Timestamp.

A data structure similar to Usage Data may be used.

\section{A.14 Trades}

\section{A.14.01 Trade Contract}

Trade Contract: name, Buyer (Counterparty), Seller (counterparty), effective start date, effective end date, Commodity, Type, Settlement Mkt., Contract Approval, Creation Date, Created By, Modification Date, Modified By, Approval Status, Buyer Comments, and Seller Comments

\section{A.14.02 Bilateral Trades}

Trade: Contract, Type, Start Date/Time, End Date/Time, Commodity, Quantity Profile; Price, Source Loc, Sink Loc., Delivery Point, A/S Provision, OASIS ID, 
Tag ID, Schedule Approval, Approval Status, Creation Date, Created By, Modification Date, Modified By,

Quantity Profile: ID, Time Interval, Value

\section{A.14.03 Market Schedules}

Market, Contract, Date, Product, resource, schedule. Scheduling data is available in MarketManager.

\section{A.14.04 P\&L Positions}

Position by customer, contract, product and region. Avalable with eterraassetoptimizer.

\section{A.14.05 Settlements and Billing}

Settlement invoices and receivables/payable positions. Available with eterrasettlements. 


\section{A.15 Appendix A - Data Structures and Summary Checklist}

\section{A.15.01 Customer Displays}

\begin{tabular}{|c|c|c|}
\hline \multicolumn{3}{|c|}{ Customer Contract Characteristics } \\
\hline Characteristic & Detail & \\
\hline $\begin{array}{l}\text { Facility Name \& } \\
\text { Location }\end{array}$ & \multicolumn{2}{|c|}{ Facility address, meters, state \& zone } \\
\hline Load Factor & \multicolumn{2}{|c|}{8760 total usage as a $\%$ of 8760 demand } \\
\hline MW (Avg.) & \multicolumn{2}{|l|}{ Average load } \\
\hline Voltage Level & \multicolumn{2}{|c|}{ Primary, Secondary, Transmission } \\
\hline Customer Class & \multicolumn{2}{|l|}{ Industry type } \\
\hline Capacity Obligations & \multicolumn{2}{|l|}{ Firm or non-firm service } \\
\hline $\begin{array}{l}\text { Start Date and Term } \\
\text { Months }\end{array}$ & \multicolumn{2}{|c|}{$12,24,36,48$ months, odd term } \\
\hline \multicolumn{3}{|c|}{$\begin{array}{c}\text { Energy Charges from SES (show result of contract unit price } X \\
\text { usage) }\end{array}$} \\
\hline \multicolumn{3}{|c|}{$\begin{array}{l}\text { Product Description \& Unit Price / Index Type (fixed price / fixed block, index w/wo } \\
\text { cap/collar, layered hedge) }\end{array}$} \\
\hline \multicolumn{3}{|c|}{$\begin{array}{l}\text { Total Energy Charge (on-peak, off-peak, other): Typical Day \& Typical } \\
\text { Month adjusted by real time usage trends }\end{array}$} \\
\hline \multicolumn{3}{|c|}{$\begin{array}{l}\text { Total Ancillary Services Charge: Typical Day \& Typical Month } \\
\text { adjusted by real time usage trends }\end{array}$} \\
\hline \multicolumn{3}{|c|}{$\begin{array}{c}\text { Other Charges: Typical Day \& Typical Month adjusted by real time } \\
\text { usage trends }\end{array}$} \\
\hline \multicolumn{3}{|c|}{$\begin{array}{l}\text { Total Balancing Charge (e.g., load Shaping, hourly, monthly, minimum } \\
\text { take discount) }\end{array}$} \\
\hline
\end{tabular}

2 Where applicable:

\begin{tabular}{|l|}
\hline Operations/Scheduling Coordination \\
\hline ISO/QSE/SC Charges/Fees \\
\hline Distribution/Transmission Losses \\
\hline $\begin{array}{l}\text { UCAP/ICAP/ACAP (a type of demand- } \\
\text { based charge) }\end{array}$ \\
\hline Network Transmission \\
\hline Intrazonal Congestion \\
\hline Unaccounted For Energy \\
\hline Interzonal Congestion \\
\hline
\end{tabular}




\section{A.16 Figure 5: Data Required for Customer Contract Tabular Display}

\begin{tabular}{|l|l|}
\hline \multicolumn{2}{|c|}{$\begin{array}{c}\text { Characteristics of Customer Graphical } \\
\text { and Tabular Displays for Rolling Data }\end{array}$} \\
\hline \multicolumn{1}{|c|}{ Characteristic } & \multicolumn{1}{|c|}{ Detail } \\
\hline $\begin{array}{l}\text { Real-time load over } 24 \mathrm{hr} \\
\text { period }\end{array}$ & By facility, state \& zone \\
\hline $\begin{array}{l}\text { Load Factor } \\
\text { MW (Avg. and peak) }\end{array}$ & Rolling, ongoing calculation \\
\hline $\begin{array}{l}\text { Rolling, ongoing calculation } \\
\text { 3revious days load (back }\end{array}$ & $\begin{array}{l}\text { Menu of load shapes to apply to contract } \\
\text { price and a weather feed with weather } \\
\text { adjustment algorithm }\end{array}$ \\
\hline Shaded-in hedged values & Over the 24 hour graphic display \\
\hline $\begin{array}{l}\text { Shaded-in non hedged } \\
\text { values }\end{array}$ & Over the 24 hour graphic display \\
\hline $\begin{array}{l}\text { Apply any past load } \\
\text { history to forecasted } \\
\text { prices (what if test) }\end{array}$ & Over the 24 hour graphic display \\
\hline Other Energy Charges \& Credits (show result of contract unit \\
price X usage)
\end{tabular}




\section{A.17 Figure 6: Data Required for Graphical and Tabular Displays of Rolling Data}

\section{A.17.01 Aggregator Displays}

\begin{tabular}{|l|}
\hline Aggregation and sort of customer contract data (above) by: \\
\hline Meter \\
\hline Contract \\
\hline Facility or site \\
\hline Utility \\
\hline Zone or Demand zone \\
\hline Node \\
\hline ISO \\
\hline Portfolio (by zone); aggregation of retail hedge by zone and load / usage \\
by zone \\
\hline $\begin{array}{l}\text { Analysis Menu for setting algorithms, conditional statements, accessing } \\
\text { weather feeds, developing and storing forecasting formulas to reflect retail } \\
\text { prices, alarms, decision/action conditions }\end{array}$ \\
\hline $\begin{array}{l}\text { Indexes: On / Off peak, real time, next day, Balance of Month, Balance of } \\
\text { Week (found in Intercontinental Exchange, Tullett Liberty) }\end{array}$ \\
\hline $\begin{array}{l}\text { Indexes Feeds: Dow Jones (SP15, NP15, COB, Palo Verde); ERCOT } \\
\text { heat rate (use gas index, Houston Shipping Channel delivery point); OR } \\
\text { (Mid-Columbia); MISO (use CINergy); NYISO; PJM }\end{array}$ \\
\hline Transmission capacities \& congestion reports \\
\hline Generation off line and coming back on line \\
\hline Gas Prices (NYMEX) \\
\hline Hydro Report (Federal site) \\
\hline Weather Feeds (weatherbank.com) \\
\hline LMP / Wholesale Price \\
\hline Alarm capability \\
\hline
\end{tabular}


A.18 Figure 7: Data Required for Aggregator Displays

Table 1: DATA PARAMETERS IDENTIFICATION TABLE

$\begin{array}{cccccccc}\text { COMMODIT } & \text { TY } & \text { WHEN } & \text { UPDATE } & \text { SOUR } & \text { DATA } & \text { COMMENTS } & \text { AUT } \\ \text { Y NAME } & \text { PE } & \text { MARK } & \text { FREQUE } & \text { CE } & \text { RESOLUTI } & & \text { O } \\ & & \text { ET } & \text { NCY } & & \text { ON (NO. } & \text { DOW } \\ & & \text { CLOS } & & & \text { INTERVAL } & \text { S } \\ & & \text { ES } & & & \text { S PER } & & \text { LOA } \\ & & & & & \text { DAY) } & \text { D? }\end{array}$

ISO

PRICES:

CAISO

HOUR-

AHEAD

ENERGY
HA 2 HOURLY CAISO HOUR S
PRIO
R TO
HOUR
24 SP15, NP15, HOURLY PALO VERDE, INTERVAL COB ZONES OF S
INTEREST

$\begin{array}{ccccc}\text { IMBALANC } & \text { RT } & \text { RT } & \text { EVERY } & \text { CAISO } \\ \text { E ENERGY } & & & 10 \\ & & & \\ & & & \\ & & & & \\ & & & & \end{array}$
$24 \times 610-$ MINUTELY INTERVAL
$S$

\begin{tabular}{|c|c|c|c|c|c|c|}
\hline $\begin{array}{l}\text { ERCOT } \\
\text { ALANCIN } \\
\text { ENERGY }\end{array}$ & RT & RT & $\begin{array}{c}\text { EVERY } \\
15 \\
\text { MINUTE } \\
\mathrm{S}\end{array}$ & $\begin{array}{c}\text { ERCOT } \\
3\end{array}$ & $\begin{array}{c}24 X \quad 4 \text { 15- } \\
\text { MINUTELY } \\
\text { INTERVAL } \\
\text { S }\end{array}$ & $\begin{array}{c}\text { HOUSTON, } \\
\text { NORTH, NE, } \\
\text { WEST, AND } \\
\text { SOUTH ZONES } \\
\text { OF INTEREST }\end{array}$ \\
\hline
\end{tabular}

\begin{tabular}{|c|c|c|c|}
\hline $\begin{array}{l}\text { PJM DA } \\
\text { ENERGY }\end{array}$ & DA & $\begin{array}{c}\text { DAY- } \\
\text { AHEA } \\
\text { D }\end{array}$ & $\begin{array}{c}\text { 4PM EST } \\
\text { DAILY } \\
\text { FOR } \\
\text { NEXT } \\
\text { DAY } \\
\text { PRICES }\end{array}$ \\
\hline
\end{tabular}

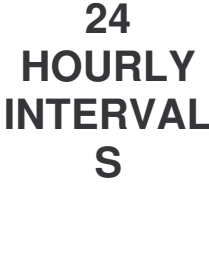

3 See weblink for data sample:

http://www.ercot.com/publicrmc/pubreportexplorer.asp?report=Market\%20Shado w\%20Prices\%20Extract 


\begin{tabular}{|c|c|c|c|c|c|c|c|}
\hline $\begin{array}{l}\text { COMMODIT } \\
\text { Y NAME }\end{array}$ & $\begin{array}{l}\text { TY } \\
\text { PE }\end{array}$ & $\begin{array}{l}\text { WHEN } \\
\text { MARK } \\
\text { ET } \\
\text { CLOS } \\
\text { ES }\end{array}$ & $\begin{array}{c}\text { UPDATE } \\
\text { FREQUE } \\
\text { NCY }\end{array}$ & $\begin{array}{c}\text { SOUR } \\
\text { CE }\end{array}$ & $\begin{array}{c}\text { DATA } \\
\text { RESOLUTI } \\
\text { ON (NO. } \\
\text { INTERVAL } \\
\text { S PER } \\
\text { DAY) }\end{array}$ & COMMENTS & $\begin{array}{c}\text { AUT } \\
\text { O } \\
\text { DOW } \\
\text { N- } \\
\text { LOA } \\
\text { D? }\end{array}$ \\
\hline $\begin{array}{l}\text { REAL-TIME } \\
\text { ENERGY }\end{array}$ & RT & RT & $\begin{array}{l}\text { EVERY } 5 \\
\text { MINUTE } \\
\mathrm{S}\end{array}$ & PJM & $\begin{array}{c}\text { 24X12 15- } \\
\text { MINUTELY } \\
\text { INTERVAL } \\
\mathrm{S}\end{array}$ & DITTO & $\mathbf{Y}$ \\
\hline $\begin{array}{l}\text { NYISO DA } \\
\text { ENERGY }\end{array}$ & DA & $\begin{array}{l}\text { DAY- } \\
\text { AHEA } \\
\text { D }\end{array}$ & $\begin{array}{c}\text { 4PM EST } \\
\text { DAILY } \\
\text { FOR } \\
\text { NEXT } \\
\text { DAY } \\
\text { PRICES }\end{array}$ & NYISO & $\begin{array}{c}24 \\
\text { HOURLY } \\
\text { INTERVAL } \\
\mathrm{S}\end{array}$ & $\begin{array}{c}\text { WEST(A), } \\
\text { GENESE(B), } \\
\text { CENTRL(C), } \\
\text { NORTH (D), } \\
\text { MHK VL (E), } \\
\text { CAPITL (F), HUD } \\
\text { VL (G), MILLWD } \\
\text { (H), DUNWOD } \\
\text { (I), N.Y.C. (J), } \\
\text { LONGIL (K), } \\
\text { HYDRO } \\
\text { QUEBEC, } \\
\text { NEPOOL, } \\
\text { ONTARIO } \\
\text { HYDRO, AND } \\
\text { PJM }\end{array}$ & $\mathbf{Y}$ \\
\hline $\begin{array}{l}\text { IMBALANC } \\
\text { E ENERGY }\end{array}$ & RT & RT & $\begin{array}{c}\text { EVERY } 5 \\
\text { MINUTE } \\
\text { S (OR } \\
\text { UP TO } \\
20 M I N)\end{array}$ & NYISO & $\begin{array}{c}24 X 12 \text { 15- } \\
\text { MINUTELY } \\
\text { INTERVAL } \\
\mathrm{S}\end{array}$ & DITTO & $\mathbf{Y}$ \\
\hline $\begin{array}{c}\text { MISO } \\
\text { BALANCIN } \\
\text { G ENERGY }\end{array}$ & RT & RT & $\begin{array}{l}\text { EVERY } 5 \\
\text { MINUTE } \\
\mathrm{S}\end{array}$ & MISO & $\begin{array}{c}\text { 24X12 15- } \\
\text { MINUTELY } \\
\text { INTERVAL } \\
\mathrm{S}\end{array}$ & $\begin{array}{l}\text { ALTERNATIVEL } \\
\text { Y, SHOW DA } \\
\text { AND RT PRICES } \\
\text { FOR CINERGY, } \\
\text { IF MISO PRICES } \\
\text { NOT YET } \\
\text { PUBLISHED. }\end{array}$ & $\begin{array}{l}\text { FUTU } \\
\text { RE }\end{array}$ \\
\hline $\begin{array}{l}\text { CINERGY } \\
\text { DA } \\
\text { ENERGY }\end{array}$ & DA & $\begin{array}{l}\text { DAY- } \\
\text { AHEA } \\
\text { D }\end{array}$ & $\begin{array}{l}\text { DAILY } \\
\text { FOR } \\
\text { NEXT } \\
\text { DAY }\end{array}$ & & $\begin{array}{c}24 \\
\text { HOURLY } \\
\text { INTERVAL }\end{array}$ & & $\mathbf{Y}$ \\
\hline
\end{tabular}




\begin{tabular}{|c|c|c|c|c|c|c|c|}
\hline $\begin{array}{l}\text { COMMODIT } \\
\text { Y NAME }\end{array}$ & $\begin{array}{l}\text { TY } \\
\text { PE }\end{array}$ & $\begin{array}{l}\text { WHEN } \\
\text { MARK } \\
\text { ET } \\
\text { CLOS } \\
\text { ES }\end{array}$ & $\begin{array}{c}\text { UPDATE } \\
\text { FREQUE } \\
\text { NCY }\end{array}$ & $\begin{array}{c}\text { SOUR } \\
\text { CE }\end{array}$ & $\begin{array}{c}\text { DATA } \\
\text { RESOLUTI } \\
\text { ON (NO. } \\
\text { INTERVAL } \\
\text { S PER } \\
\text { DAY) }\end{array}$ & COMMENTS & $\begin{array}{l}\text { AUT } \\
\text { O } \\
\text { DOW } \\
\text { N- } \\
\text { LOA } \\
\text { D? }\end{array}$ \\
\hline & & & PRICES & & S & & \\
\hline $\begin{array}{c}\text { CINERGY } \\
\text { RT ENERGY }\end{array}$ & RT & RT & $\begin{array}{l}\text { EVERY } 5 \\
\text { MINUTE } \\
\text { S }\end{array}$ & & $\begin{array}{c}\text { 24X12 15- } \\
\text { MINUTELY } \\
\text { INTERVAL } \\
\text { S }\end{array}$ & & $\mathbf{Y}$ \\
\hline$\frac{\text { OTHER ISO }}{\text { DATA: }}$ & & & & & & & \\
\hline $\begin{array}{l}\text { TRANSMISS } \\
\text { ION } \\
\text { RESERVATI } \\
\text { ONS }\end{array}$ & TR & & & $\begin{array}{l}\text { WHICH } \\
\text { ISOS }\end{array}$ & & $\begin{array}{l}\text { SPECIFY WHICH } \\
\text { ZONES OF } \\
\text { INTEREST }\end{array}$ & $\begin{array}{c}\text { FUTU } \\
\text { RE }\end{array}$ \\
\hline $\begin{array}{c}\text { GENERATO } \\
\text { R } \\
\text { AVAILABILI } \\
\text { TY - } \\
\text { ONLINE } \\
\text { REPORT }\end{array}$ & GA & & & $\begin{array}{l}\text { WHICH } \\
\text { ISOS }\end{array}$ & & $\begin{array}{l}\text { SPECIFY WHICH } \\
\text { ZONES OF } \\
\text { INTEREST }\end{array}$ & $\begin{array}{c}\text { FUTU } \\
\text { RE }\end{array}$ \\
\hline $\begin{array}{c}\text { GENERATO } \\
\text { R - OFFLINE } \\
\text { REPORT }\end{array}$ & GA & & & $\begin{array}{l}\text { WHICH } \\
\text { ISOS }\end{array}$ & & $\begin{array}{l}\text { SPECIFY WHICH } \\
\text { ZONES OF } \\
\text { INTEREST }\end{array}$ & $\begin{array}{c}\text { FUTU } \\
\text { RE }\end{array}$ \\
\hline $\begin{array}{l}\text { HYDRO } \\
\text { REPORT }\end{array}$ & GA & & & & & & $\begin{array}{l}\text { FUTU } \\
\text { RE }\end{array}$ \\
\hline $\begin{array}{l}\text { BALANCE } \\
\text { OF THE } \\
\text { MONTH } \\
\text { ENERGY }\end{array}$ & FE & DAILY & DAILY & $\begin{array}{l}\text { TULLE } \\
\text { TT } \\
\text { LIBER } \\
\text { TY }\end{array}$ & $\begin{array}{c}1 \\
\text { MONTHLY } \\
\text { PRICE PER } \\
\text { TRADING } \\
\text { HUB }\end{array}$ & $\begin{array}{c}\text { ERCOT HEAT } \\
\text { RATE, NP15, } \\
\text { SP15, PALO } \\
\text { VERDE, COB, } \\
\text { NOB, MID-C } \\
\text { ARE TRADING } \\
\text { HUBS OF } \\
\text { INTEREST: }\end{array}$ & $\begin{array}{c}\text { Y, } \\
\text { USER } \\
- \\
\text { ENTR } \\
Y\end{array}$ \\
\hline $\begin{array}{l}\text { BALANCE } \\
\text { OF THE } \\
\text { WEEK }\end{array}$ & FE & DAILY & DAILY & $\begin{array}{c}\text { TULLE } \\
\text { T } \\
\text { LIBER }\end{array}$ & $\begin{array}{l}1 \text { WEEKLY } \\
\text { PRICE PER } \\
\text { TRADING }\end{array}$ & DITTO & $\begin{array}{l}\text { Y, } \\
\text { USER } \\
-\end{array}$ \\
\hline
\end{tabular}




\begin{tabular}{|c|c|c|c|c|c|c|c|}
\hline $\begin{array}{l}\text { COMMODIT } \\
\text { Y NAME }\end{array}$ & $\begin{array}{l}\text { TY } \\
\text { PE }\end{array}$ & $\begin{array}{l}\text { WHEN } \\
\text { MARK } \\
\text { ET } \\
\text { CLOS } \\
\text { ES }\end{array}$ & $\begin{array}{l}\text { UPDATE } \\
\text { FREQUE } \\
\text { NCY }\end{array}$ & $\begin{array}{l}\text { SOUR } \\
\text { CE }\end{array}$ & $\begin{array}{c}\text { DATA } \\
\text { RESOLUTI } \\
\text { ON (NO. } \\
\text { INTERVAL } \\
\text { S PER } \\
\text { DAY) }\end{array}$ & COMMENTS & $\begin{array}{c}\text { AUT } \\
\text { O } \\
\text { DOW } \\
\text { N- } \\
\text { LOA } \\
\text { D? }\end{array}$ \\
\hline ENERGY & & & & TY & HUB & & $\begin{array}{c}\text { ENTR } \\
\mathbf{Y}\end{array}$ \\
\hline $\begin{array}{c}\text { HEAT RATE } \\
\text { FOR } \\
\text { HOUSTON } \\
\text { SHIP } \\
\text { CHANNEL }\end{array}$ & GI & & & & & & $\begin{array}{c}\text { FUTU } \\
\text { RE }\end{array}$ \\
\hline $\begin{array}{c}\text { DOW } \\
\text { JONES } \\
\text { INDEX DA } \\
\text { ENERGY } \\
\text { ON-PEAK \& } \\
\text { OFF-PEAK }\end{array}$ & El & & & & & & $\begin{array}{c}\text { FUTU } \\
\text { RE }\end{array}$ \\
\hline $\begin{array}{c}\text { MID } \\
\text { COLUMBIA } \\
\text { ELECTRIC } \\
\text { INDEX FIRM } \\
\text { ENERGY }\end{array}$ & EI & & & & & & $\begin{array}{c}\text { FUTU } \\
\text { RE }\end{array}$ \\
\hline $\begin{array}{c}\text { NON-FIRM } \\
\text { ENERGY }\end{array}$ & EI & & & & & & $\begin{array}{c}\text { FUTU } \\
\text { RE }\end{array}$ \\
\hline $\begin{array}{l}\text { GAS PRICE } \\
\text { INDEX }\end{array}$ & GI & & & & & $\begin{array}{c}\text { ERCOT HEAT } \\
\text { RATE, NP15, } \\
\text { SP15, PALO } \\
\text { VERDE, COB, } \\
\text { NOB, MID-C } \\
\text { ARE TRADING } \\
\text { HUBS OF } \\
\text { INTEREST: }\end{array}$ & $\begin{array}{c}\text { FUTU } \\
\text { RE }\end{array}$ \\
\hline $\begin{array}{l}\text { WEATHER } \\
\text { FEED }\end{array}$ & W & & & $\begin{array}{c}\text { WEAT } \\
\text { HERBA } \\
\text { NK.CO } \\
\text { M }\end{array}$ & & $\begin{array}{c}\text { TEMPERATURE } \\
\text { IN DEGREE } \\
\text { DAYS }\end{array}$ & $\begin{array}{c}\text { FUTU } \\
\text { RE }\end{array}$ \\
\hline
\end{tabular}


$\mathrm{RT}$ = Real-time energy

$\mathrm{DA}=$ Day ahead energy

$\mathrm{HA}=$ Hour-ahead energy

$\mathrm{TR}=$ Transmission reservation

$\mathrm{FE}=$ Forward energy

$\mathrm{GA}=$ Generation availability

$\mathrm{W}=$ Weather

$\mathrm{EI}=$ Electric energy index

$\mathrm{Gl}=\mathrm{Gas}$ index 


\section{A.19 Appendix B - Data Models}

\section{A.19.01 Customer Data}

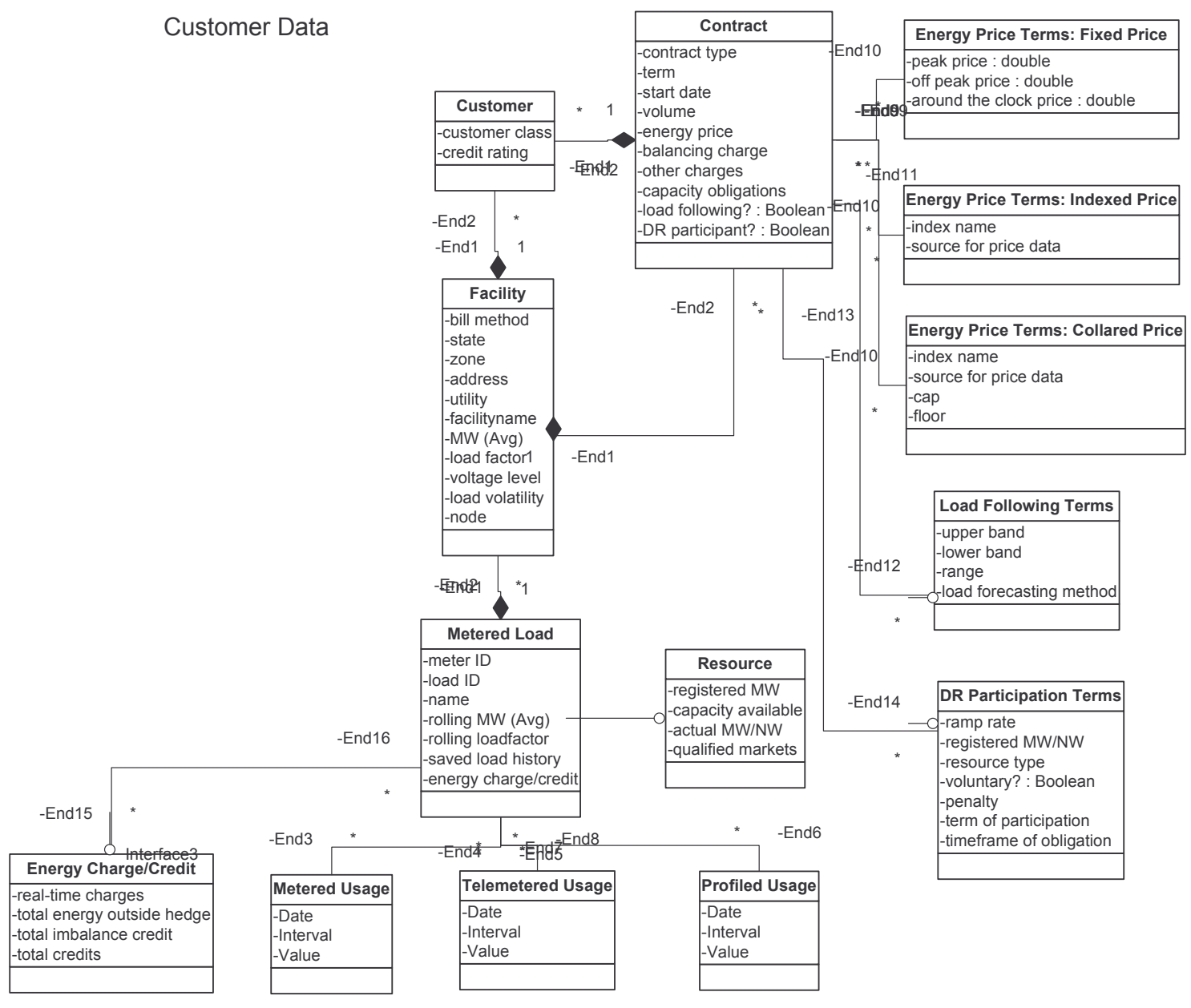




\section{A.19.02 Market Data}

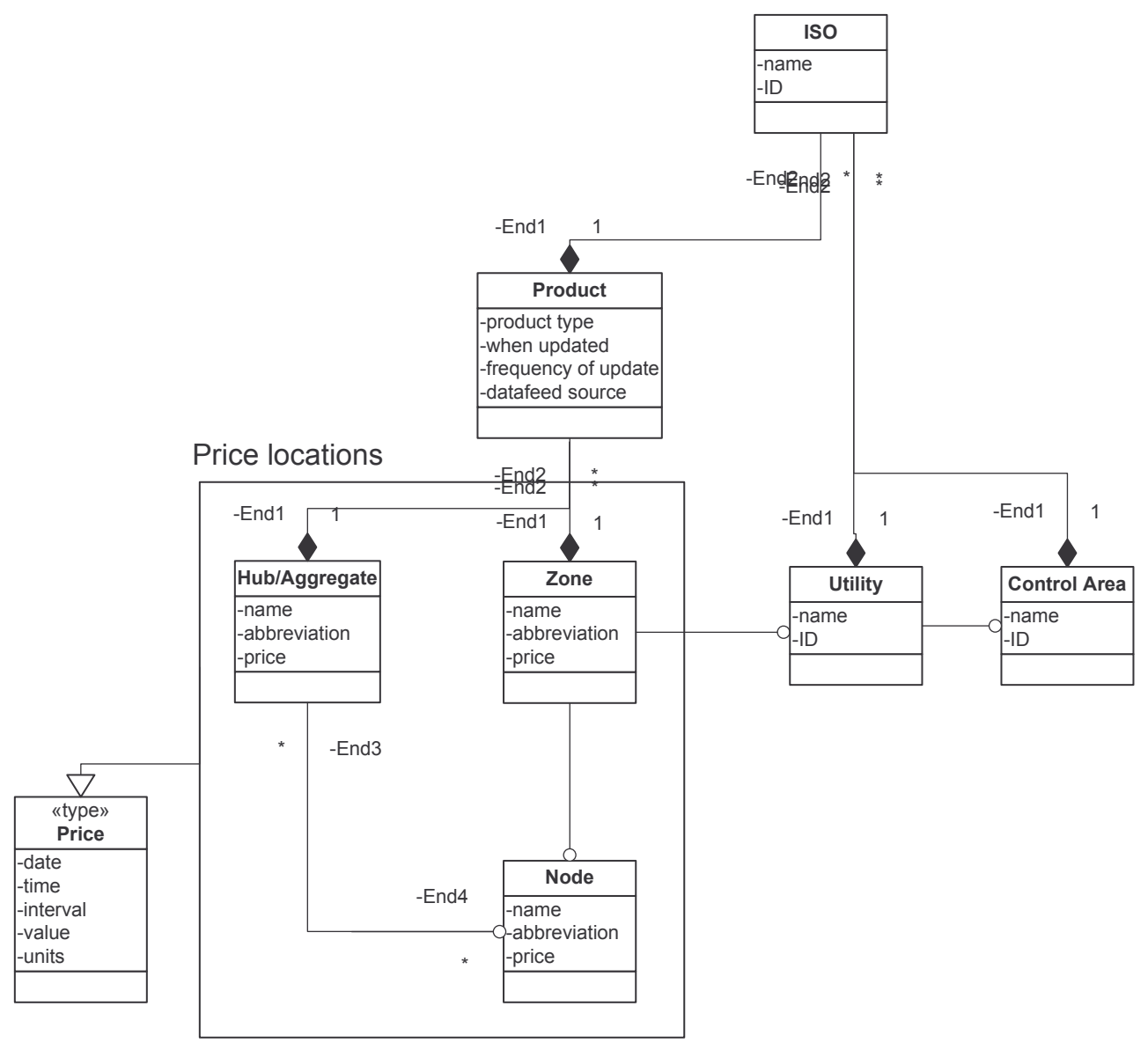




\section{A.20 APPENDIX C - USE CASES}

\section{A.20.01 Scheduler}

\section{A.20.02 Overview:}

The Scheduler works on optimizing use of existing portfolios 4 on a day-before and day-of basis. The Scheduler aggregates usage information to sharpen up his demand forecast. He determines the delta between actual usage and forecasted usage so he can sell/buy any excess supply. He does so by aggregating usage information by demand zone or other criteria and then transacting in the dayahead and day-of markets as opportunities arise.

Any information feeds that affect the ability to match supply with demand are helpful to the Scheduler, such as actual usage by zone, power plant outages, and transmission system availability. The information he requires is listed below, along with "nice-to-have" type information, and required functionality.

\section{A.20.03 Information required:}

- Actual usage (particularly for load-following customers)

- Day-ahead and day-of ISO market prices (ERCOT, PJM, NYISO, and CAISO)

\section{A.20.04 Information that is nice to have:}

- Balance of the Month prices (balmo) for all trading hubs in CAISO, ERCOT, and PJM.

- Balance of the Week prices (balweek)

- Transmission reservations

- Generation online/offline report (to determine when generation coming back online)

- Hydro availability

\section{A.20.05 Functionality required:}

- Aggregation of usage data by ISO, Zone, Demand Zone, UDC, Meter, Customer, and types of Retail contracts.

- Configurable automatic alarming based on preset thresholds that trigger off of market price, aggregated usage, or an algebraic expressions configured by Scheduler.

For example:

- Scheduler configures a "delta" algebraic expression indicating his exposure.

4 The portfolio is put together (on a month to month basis) by a Portfolio Manager before it's passed to the Scheduler. 
- He enters his mark-to-market price, and the percentage above and below that price by which he is to be alerted.

- He selects to be alerted if the real-time price or next-day price (or balmo or balweek price, if available) in his selected zone of interest exceeds the threshold band.

- Export of aggregated usage information saved in Excel format with contents of columns selectable and configurable by user.

- Manual (or electronic) entry of portfolio position to support alert off of P\&L computation.

For example:

- Scheduler enters 24 values that represent a zonal portfolio position for a given day

- Scheduler enters balmo value in order to calculate his P\&L position

- Scheduler configures an alarm that triggers based on his P\&L position, which fluctuates according to actual usage of telemetered customers within a zone.

\section{A.21 End-Use Customer}

\section{A.21.01 Overview:}

After an end-use customer establishes a retail contract for the purchase of electricity with an Aggregator, the customer is subject to paying a retail price per contract agreement. The retail price may be fixed over the contract term or fluctuate according to a price index identified in the contract. Actual electricity costs paid the customer depend on its actual usage and retail price paid for any given hour. To more actively manage its electricity cost risk, the customer accesses estimates of its retail price on a day-ahead as well as day-of basis, considers its next-day forecasted usage as well as actual real-time usage, and adjusts its electricity consumption accordingly.

\section{A.21.02 Functionality required:}

- Access the graphical display shown in Figure 2 of this document to view its estimated retail price, contracted volume, and actual usage (assuming its usage is telemetered). The graphical display plots usage and contracted volume (in MW) on one $y$-axis and retail price on a secondary $y$-axis, all over a 24-hour period.5

5 On the graphical display, periods of over-hedge or under-hedge are readily apparent by comparing hedged volume to actual usage of a telemetered customer. 
- The customer may choose to view information for any facility belonging to the customer.

- The customer may choose to view information in aggregate for all meters belonging to the customer (aggregated by facilities, contract, ISO, Zone or Demand zone)

- View tabular display of own retail contract information as listed in Figure 5 of this document. 6

- View real-time charges to the customer as per retail contract

- Output into Excel.

\section{A.21.03 Functionality that is nice to have:}

- The customer selects a date range within the last 90 days to graphically view its historical usage.

- The customer selects a date range within the last 90 days to view its historical usage in a tabular format.

- View rolling ongoing calculations as listed in Figure 6 of this document (e.g., load factor, Avg. and peak MW)

- Manual update of forecasted usage by the customer.7

- Access graphical display of forecasted usage and associated forecasted retail price as in Figure 2.

- Perform what-if cost studies:

- Select a single or block of dates from the calendar in Figure 1 for which to create a usage profile or aggregated usage profile

- Use result to compute what-if cost scenarios based on customer's current retail contract.

- Compare resulting what-if cost against another scenario.

\section{A.22 Aggregator}

\section{A.22.01 Overview:}

After the Aggregator establishes a retail contract for the purchase of electricity with an end-use customer, the Aggregator monitors the contract's progress retail price per contract agreement. The retail price may be fixed over the contract term or fluctuate according to a price index identified in the contract. Actual electricity costs paid the customer depend on its actual usage and retail price paid for any given hour. To more actively manage its electricity cost risk, the customer accesses estimates of its retail price on a day-ahead as well as day-of basis, considers its next-day forecasted usage as well as actual real-time usage, and adjusts its electricity consumption accordingly.

6 The retail contract information consists mainly of standing data that has been previously provided by the Aggregator

7 Assumes the Aggregator previously has provided an initial forecast of usage per customer (based on historical load). 


\section{A.22.02 Functionality required:}

- Manual or electronic entry of customer retail contract information (at least for all customers telemetered).

- Aggregation of contracts by ISO, Zone, Demand Zone, UDC, Meter, Customer, and types of Retail contracts.

- Access aggregated usage and volume information as in Figure 3 (similar to Customer Graphical Display, but aggregated by zone).

- Access the ISO imbalance market prices for a selected zone.

- Specify algebraic expressions and conditional statements by which to set thresholds for automatic alarming based on selected zonal market price and aggregated information.

- Output of tabular data to Excel

\section{A.22.03 Functionality that is nice to have:}

- Configurable reports

- Specify algebraic expressions by which to define retail contract terms.

- Access gas indices

- Access forward curves

- Access weather feeds

- Functionality for developing and storing forecasting formulas

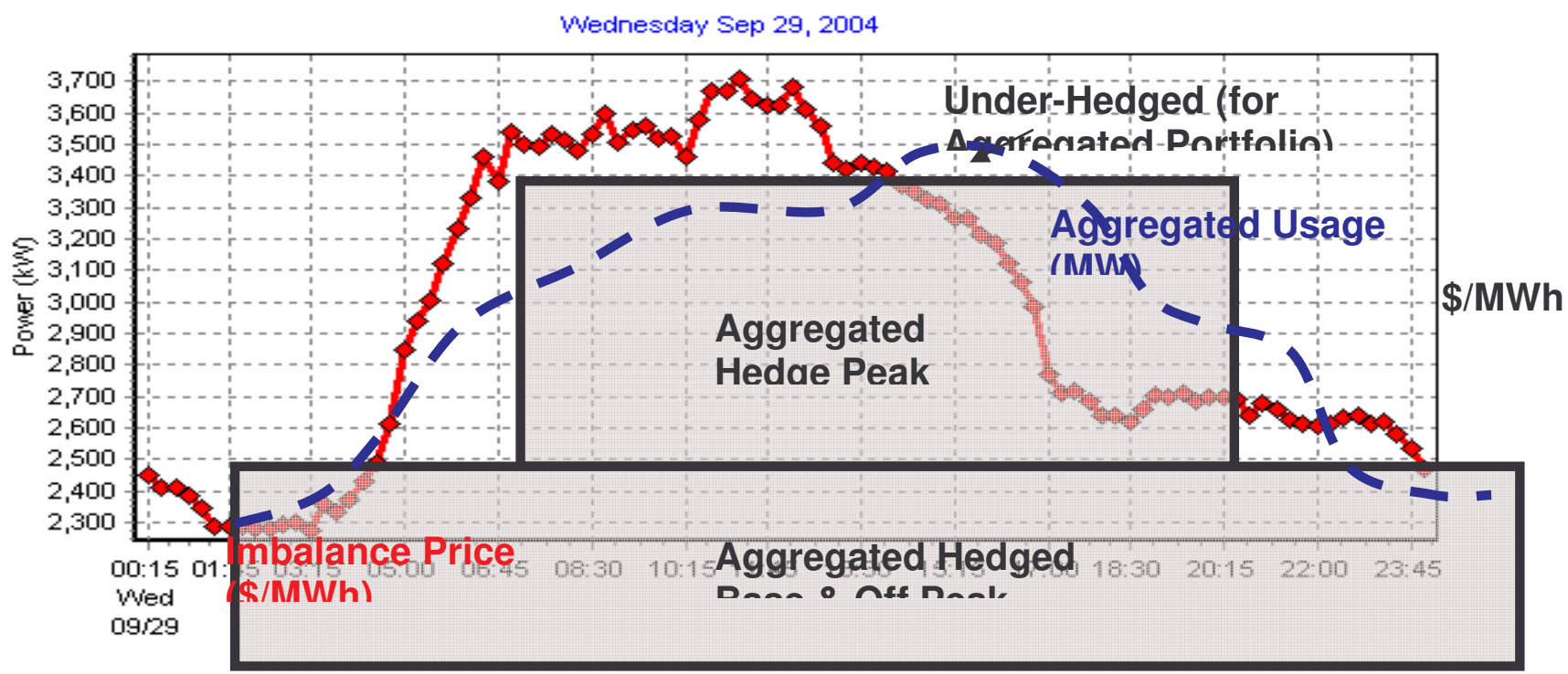




\title{
Appendix B - Metered Data Collection Over WAN with e-terracontrol
}

\author{
January, 2005
}


TABLE OF CONTENTS

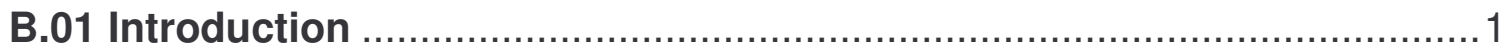

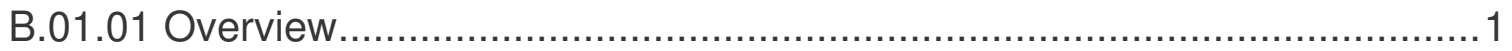

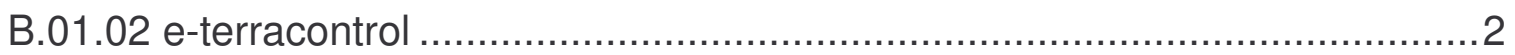

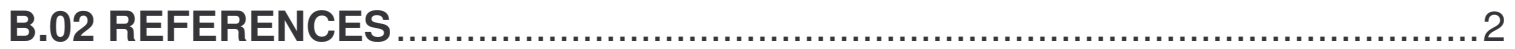

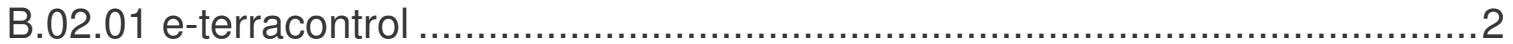

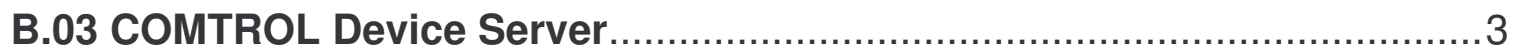

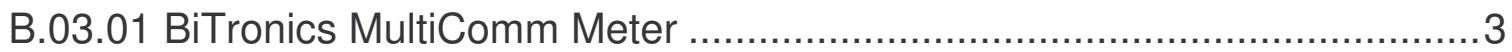

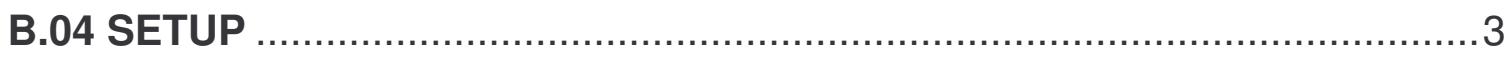

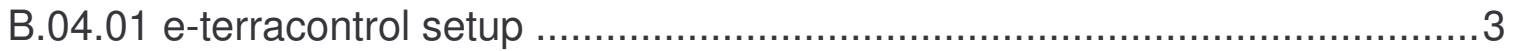

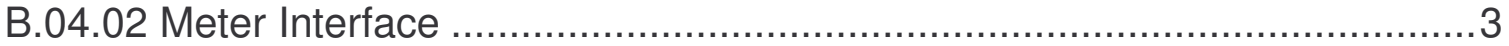

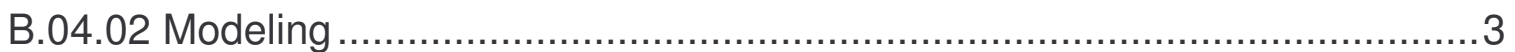

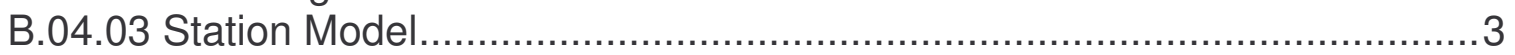

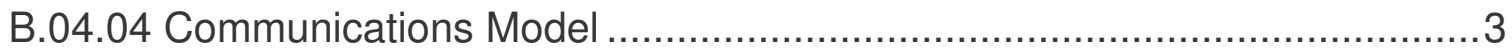

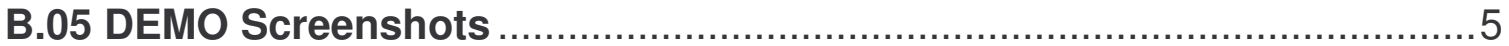

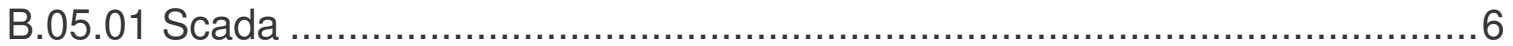

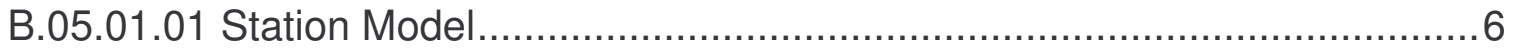

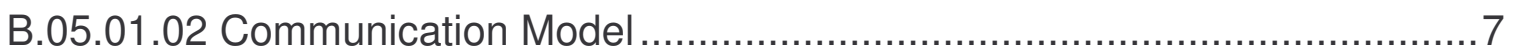




\section{B.01 Introduction}

\section{B.01.01 Overview}

This document describes application of e-terracontrol for data collection from a Meter over WAN. The demo setup used is based on DNP3.0 Bitronics MultiComm Meter with COMTROL DeviceMaster Pro device server. This document describes the necessary steps involved in setting up e-terracontrol.
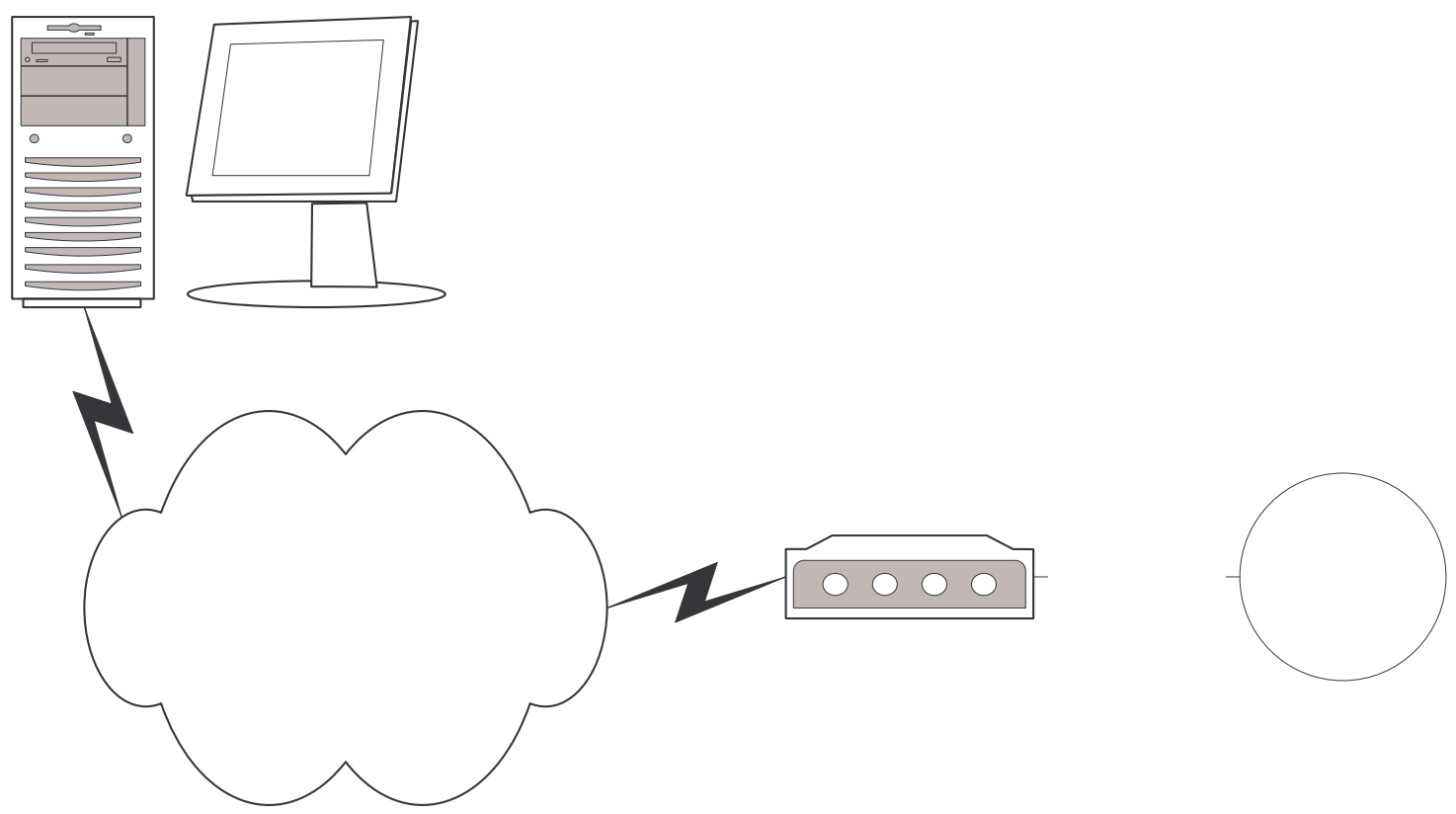

Fig. 1 Overview 


\section{B.01.02 e-terracontrol}

The major of components that are of interest in this document are SCADA , CFEREADER and e-terrabrowser. The Fig. 2 shows the overview of the these components.
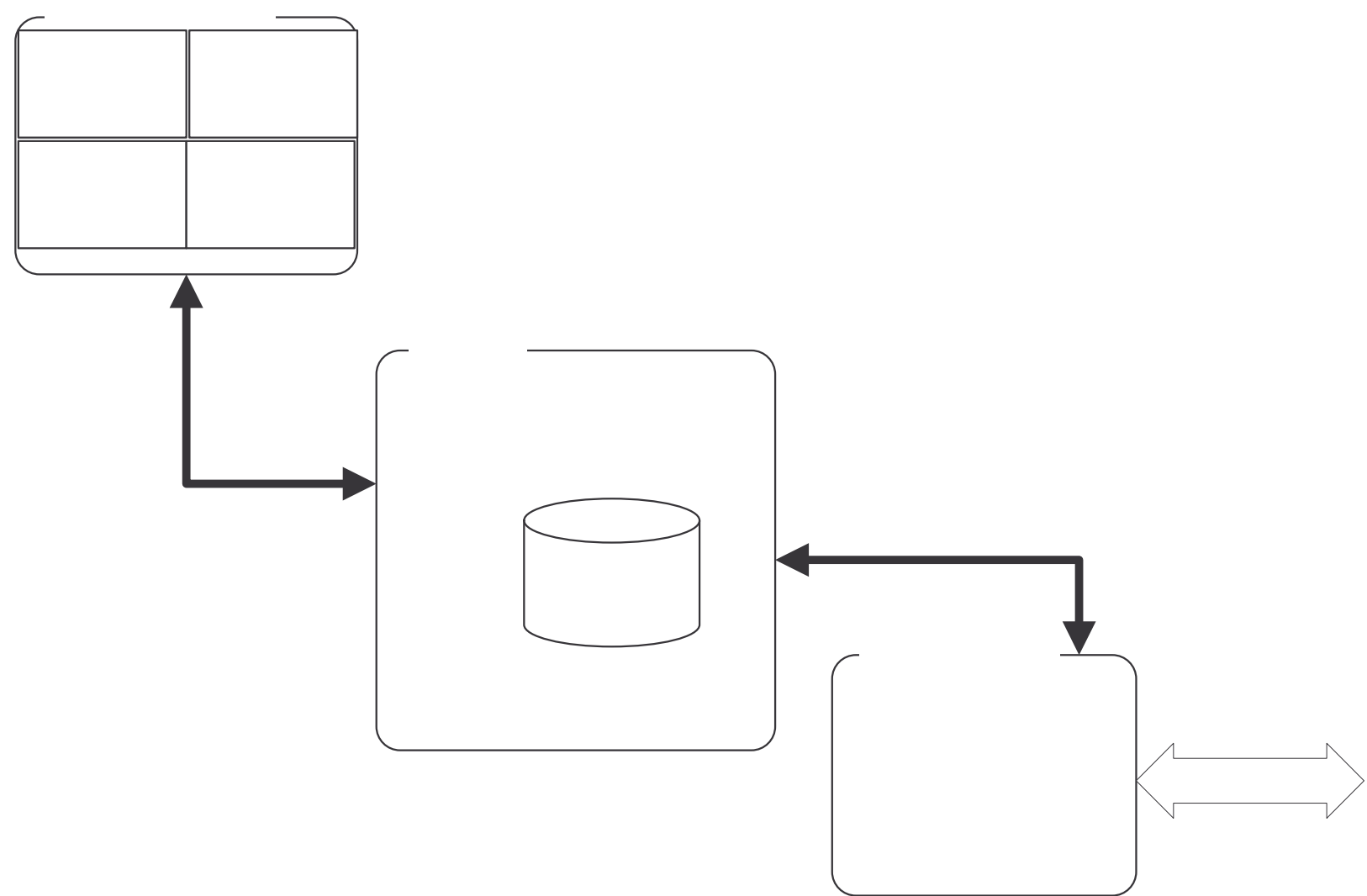

\section{B.02 REFERENCES}

\section{E-terrabrowser}

Refer to the following documencationfortitutication

\section{B.02.01 e-terracontrol}

e-terracontrol reference manual.

e-terracontrol Protocol Modeling guide.
Event/Alarm Status List 


\section{B.03 COMTROL Device Server}

\section{B.03.01 BiTronics MultiComm Meter \\ DNP3.0 Interface Option Manual. \\ B.04 SETUP}

\section{B.04.01 e-terracontrol setup}

- Install e-terracontrol version 3.3, e-terrabrowser 3.3.

- Install the COMTROL DeviceMasterPro driver. Configure the Driver with required IP address of the COMTROL device server and individual port configuration.

\section{B.04.02 Meter Interface}

The MultiComm physical layer is either 3 wire RS232 (RX-TX-COM) or 2 wire RS485.The COMTROL DeviceMaster Pro device server ports supports configurability of RS232/485 Ports. Refer to COMTROL documentation on the DeviceMaster Pro for further details.

\section{B.04.02 Modeling}

e-terracontrol model information is organized between station model, types, data sources and communication model. Please refer to eterracontrol documentation on details on the modeling. Refer to Cfereader section in the e-terracontrol reference manual for details on cfereader modeling. Refer to e-terracontrol protocol modeling guide for DNP specific modeling.

\section{B.04.03 Station Model}

Refer to the e-terracontrol reference manual for details on station modeling. Model a device for each meter and model required measurements along with digital controls and set points.

\section{B.04.04 Communications Model}

This section describes the specific modeling related to the DNP3.0 protocol.

Please refer to e-terracontol protocol modeling guide for modeling guidelines and BiTronics Multicomm DN3.0 Interface option manual for DNP3.0 Protocol Support of the meter.

The Multicomm meter is DNP3.0 Level1 Slave. It has configurable slave address from 0-255. The meter Communicates on 9600 baud, 8 data bits, 1 stop bit , no parity.

The MultiComm meter supports 297 Analog Input measurements, 532 bit Binary counter measurements, 4 binary outputs and 15 analog outputs.

After modeling a generic Cfereaeder dataset and Cfe dataset, Model a path dataset for each com port and an RTU dataset for each meter connected on a port. 


\section{CFE Dataset:}

The PCL Parameter on CFE Dataset PCL200 determines the master station address. In the case of Multicomm meter do not specify any particular master station address, so any value or the default value also works.

\section{Port Dataset:}

The Port Dataset check for following parameters

Baudrate $=9600$

PortAddress $=$ COMxx [Port address on which the meter is connected]

Also add the following PCL parameters on the port dataset

PCL292 = HANDSHAKE:0

PCL281 $=$ NOFLOW:0

\section{RTU Dataset:}

Check for the following parameters on the RTU Datset

RTUAddress $=1$ [ The Multicomm DNP3.0 Slave address]

PCL252 = DNPLEVEL:1 [ Set the Slave DNP support level to 1]

\section{Scangroup datasets:}

Model a periodic scan group for scanning analogs and status and a non periodic scan group for counters, another non periodic scan group for digital controls/analog setpoints.

On the periodic scan group make sure that the scanrate and integrity rates are set correctly.

Model an analog card dataset with a count of 297 dataitems. Fill the the dataitem fields. Set the PCL parameter PCL209== Al:32 [ 32 Bit Analog].

The counters are read on a timer defined by a read timer in the model.

On the non periodic counter scangroup, make sure that

read timers are defined in the timers

the read timer is assigned to the cfereader dataset.

Accumname_xx parameter is defined in the cfereader dataset.

Accumname $=x x$ is assigned in the dataset.

Please refer to the e-terracontrol protocol modeling guide dnp section for accumulator modeling. 
Model a counter card with 5 dataitems. Also check for the PCL parameter PCL211 = BINCNT:32.

Model digital control card with required number of controls and also model an analog setpoint card with required number of setpoints.

Link the data items in the cards to corresponding station measurements.

\section{B.05 DEMO Screenshots}

Following are the screenshots of Measurement List, Communication Status, Cfereader, scada from the demo test system. 


\section{B.05.01 Scada \\ B.05.01.01 Station Model}

Eile Edit Insert View Iest Help

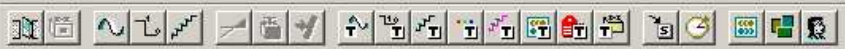

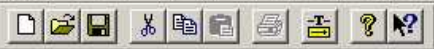

\begin{tabular}{|c|c|}
\hline Database | L & $\log \mid$ Statistics $\mid$ \\
\hline \multirow{2}{*}{\multicolumn{2}{|c|}{ 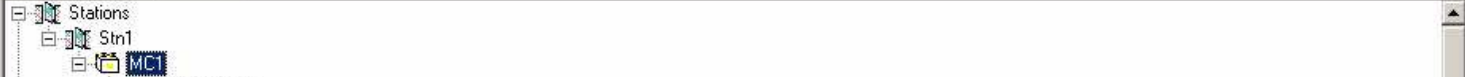 }} \\
\hline & \\
\hline \multirow{2}{*}{\multicolumn{2}{|c|}{$\sim$ Health Check }} \\
\hline \multirow{2}{*}{\multicolumn{2}{|c|}{$\begin{array}{l}\sim \text { Amp. Phase A } \\
\simeq \text { Amp. Phase B }\end{array}$}} \\
\hline & \\
\hline \multicolumn{2}{|r|}{ A Amp. Phase C } \\
\hline & $\sim$ Votls PhaseA.N \\
\hline \multicolumn{2}{|r|}{$\begin{array}{l}\simeq \text { Vots PhaseA-N } \\
\approx \text { Volts PhaseB-N }\end{array}$} \\
\hline \multirow{2}{*}{\multicolumn{2}{|c|}{$\begin{array}{l}\tilde{W} \text { Volls PhaseC-N } \\
\approx \text { Watts Total } 3 \text { Phase }\end{array}$}} \\
\hline & \\
\hline \multicolumn{2}{|r|}{$\begin{array}{l}\mathrm{U} \text { VARS Total } 3 \text { Phase } \\
\text { Watts Phase } \mathrm{A}\end{array}$} \\
\hline \multicolumn{2}{|r|}{$\begin{array}{l}\text { W Watts Phase A } \\
\approx \text { Watts Phase B }\end{array}$} \\
\hline \multicolumn{2}{|r|}{$\begin{array}{l}\text { W Watts Phase B } \\
\text { Watts Phase C }\end{array}$} \\
\hline \multicolumn{2}{|r|}{ U VARS Phase A } \\
\hline \multirow{2}{*}{\multicolumn{2}{|c|}{$\begin{array}{l}\approx \text { VARS Phase B } \\
\sim \text { VARS Phase C }\end{array}$}} \\
\hline & \\
\hline \multicolumn{2}{|r|}{$+\sim \mathrm{CT}$ value } \\
\hline \multirow{2}{*}{\multicolumn{2}{|c|}{$\begin{array}{l}\text { F } \sim \text { CT Divisor } \\
\text { TPT Value }\end{array}$}} \\
\hline & \\
\hline \multicolumn{2}{|r|}{$\sim$ PT Divisor } \\
\hline \multicolumn{2}{|r|}{ ¿N. Current } \\
\hline \multicolumn{2}{|r|}{$\begin{array}{l}\tilde{\sim} \text { Freq } \\
\approx \text { VAs Phase A }\end{array}$} \\
\hline \multicolumn{2}{|r|}{$\sim$ VAs Phase B } \\
\hline \multicolumn{2}{|r|}{$\begin{array}{l}\text { ¿ VAs Phase C } \\
\text { V VAs Total }\end{array}$} \\
\hline \multirow{2}{*}{\multicolumn{2}{|c|}{ UPF PhaseA }} \\
\hline & \\
\hline \multicolumn{2}{|r|}{$\sim$ PF Phase B } \\
\hline & $\sim$ PF Total \\
\hline & \\
\hline \multicolumn{2}{|r|}{$\sim$ Comm Fw Rev. } \\
\hline \multicolumn{2}{|r|}{$\begin{array}{l}\text { U Host Fw Rev. } \\
\sim \text { Micro Fw Rev. }\end{array}$} \\
\hline \multirow{2}{*}{\multicolumn{2}{|c|}{$\begin{array}{l}\text { 工 Present Demand Amps A } \\
\sim \text { Present Demand Amps B }\end{array}$}} \\
\hline & \\
\hline & $\sim$ Present Demand Amps C \\
\hline & $\sim$ Present Demand Amps $N$ \\
\hline & $\sim$ Present Demand Volts A \\
\hline & $\sim$ Present Demand Volts B \\
\hline & $\sim$ Present Demand Volts C \\
\hline & $\sim$ Max. Demand Volts A \\
\hline & $\sim$ Max. Demand Volts B \\
\hline & $\sim$ Max. Demand Volts C \\
\hline & $\sim$ Min. Demand Volts A \\
\hline & $\sim$ Min. Demand Volls B \\
\hline & 工 Min. Demand Volts $C$ \\
\hline & ح Present Dem. Watts Total \\
\hline
\end{tabular}




\section{B.05.01.02 Communication Model}

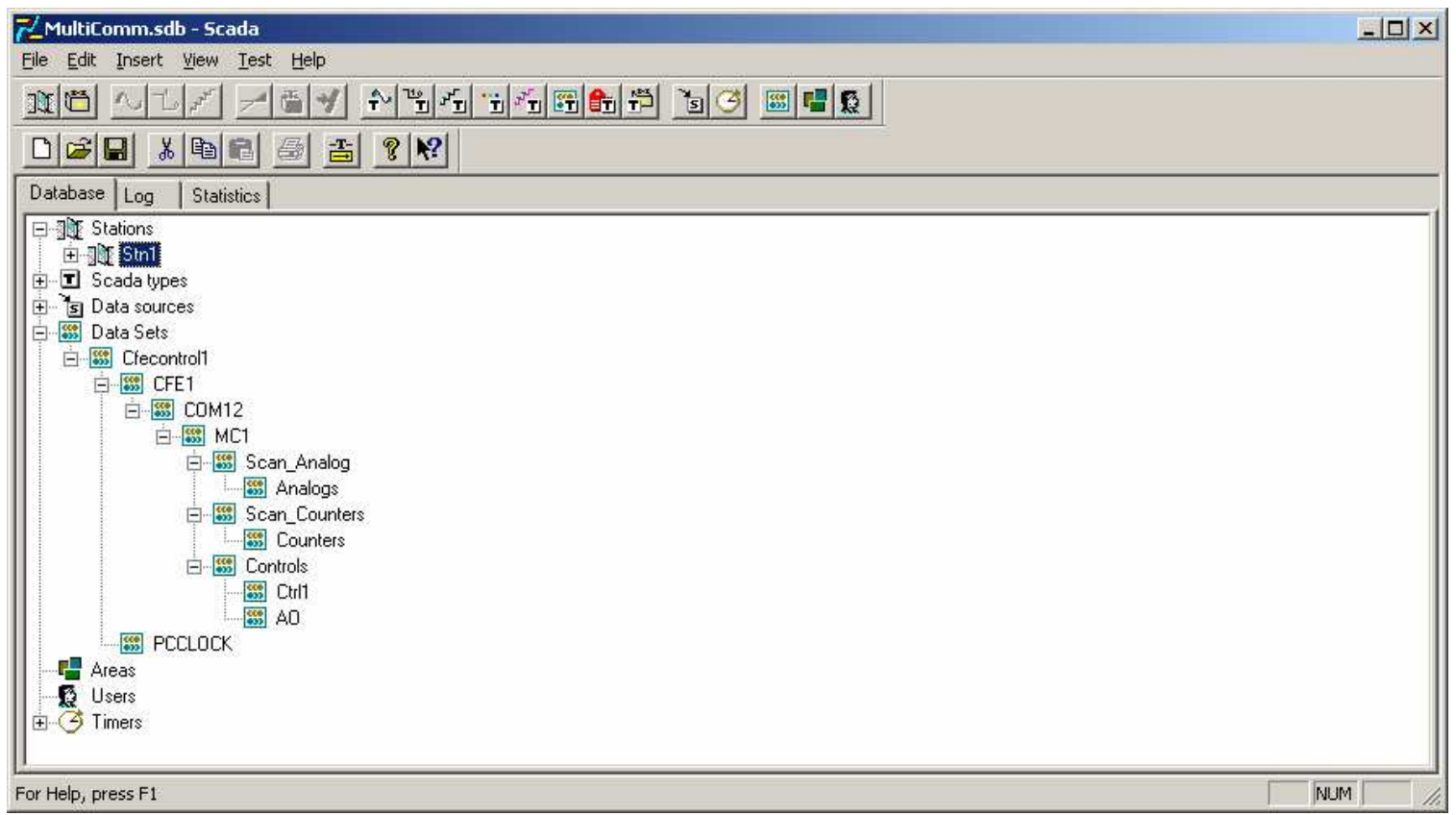




\section{Appendix C - Configuration Tech Note - Comtrol DeviceMaster Pro "Socket Server"}

Created on January 17 th by Bob Klein

Reviewed on January $20^{\text {th }}$ by Arne Anderson

Updated on March $7^{\text {th }}$ by Bob Klein

\section{C.01 Introduction / Overview}

The purpose of this document is to assist in the integration of the Comtrol

DeviceMaster Pro into an existing internet ready network, and establish connectivity back to an Areva E-terracontrol front end processor. The DeviceMaster Pro provides the Ethernet-to-Serial solution to establish communications over the internet to pull real time values from serial devices such as meters, relays, or RTU's.

The DeviceMaster Pro offers the communications interface to meet the Department of Energy's requirement for data acquisition of reading power meters over the internet configured with DNP protocol. The DeviceMaster Pro will pass the requests from the E-terracontrol system, and pass the responses from the meters. The data provided from the meters is saved into the E-terracontrol system.

\section{C.02 Hardware and Software required}

\begin{tabular}{|l|l|}
\hline Description & Part\# \\
\hline $\begin{array}{l}\text { Windows 2000,XP,2003 system } \\
\text { (HW) }\end{array}$ & \\
\hline $\begin{array}{l}\text { Internet service for the Windows } \\
\text { system }\end{array}$ & \\
\hline Comtrol DeviceMaster Pro (HW) & DB9M 8-port Part\#3000202 (black box) \\
\hline Comtrol's PortVision (SW) & \\
\hline $\begin{array}{l}\text { Internet service for the } \\
\text { DeviceMaster Pro }\end{array}$ & \\
\hline
\end{tabular}

\section{C.03 Documentation used to create this document}

\begin{tabular}{|l|l|}
\hline Description & Filename \\
\hline DeviceMaster Pro User Guide & Pro_Guide.pdf (found on CD, or \\
& Comtrol's internet page \\
& http://support.comtrol.com/download.a \\
& sp) \\
\hline Comtrol's PortVision (SW) & Provided with CD and also found on \\
& Comtrol's website \\
& http://support.comtrol.com/download.a \\
& sp \\
\hline
\end{tabular}


C.04 Process used to configure the DeviceMaster Pro's network. The following process will step you through the configuration of the Comtrol DeviceMaster Pro. The network interface will be configured with an IP address, and the serial port(s) will be configured with a socket port number unique to all ports.

- Obtain an IP address from your IT department, or network support specialist for the network to receive the new Comtrol DeviceMaster Pro.

- Connect the Comtrol DeviceMaster Pro and a PC to a local network. The PC will need PortVision installed. This PC requires Windows 2000,XP,or 2003, and can be considered as a maintenance PC.

- Install Comtrol's PortVision software to a PC to be used for configuring the DeviceMaster Pro units. The PC should be connected to the same network as the DeviceMaster Pro. The software comes with the CD, and is also available on Comtrol's website http://support.comtrol.com (version 2.02 was used to create this document)

Here are the default network settings which will be shown in later steps. IP:192.168.250.250 Subnet: 255.255.0.0 Gateway:192.168.250.1 The PC does not need to be in the same network subnet. PortVision will detect the MAC address allowing the user to login

- From your PC start PortVision from Start|Programs $\backslash$ Comtrol|PortVision\PortVision

Click on Scan Network, and your device with MAC address should appear.

Double click on your device and you should see the Configure Device window.

- Enter the IP address provided by the IT department, subnet mask, default gateway, and click Apply Changes. Takes about 30 seconds to complete

- If you PC is in the same subnet you should be able to ping the DeviceMaster IP address. Start a command prompt by clicking on StartlRun, and typing CMD then enter. A command window will appear, and now type PING <IP address > enter. Talk to your IT department, or network specialist for details about using the PING command. Command is PING Xxx.xxx.xxx.xxx

- Now let's increase the DeviceMaster Pro's timeout. It's recommended that you increase the TIMEOUT within Comtrol's RedBoot> prompt. The following steps will connect you to RedBoot>, and assist in changing the timeout value. For more details search for RedBoot in the Pro_Guide.pdf document.

a To log into RedBoot> you will need to start, and setup a terminal session (HyperTerminal, or TTY) of the PC's to Com1. Set the terminal session settings to: 57600,8 bit, no parity, flow control=none

- Connect the PC's Com1 port to the DeviceMaster Pro Com1 by using a Db9 RS232 null-modem cable. This be included with the DeviceMaster unit.

- Now go to the PortVision program and reboot the DeviceMaster.

Return to the terminal session and within 15 seconds enter the following \#!DM enter. RedBoot> should appear. 
- At the RedBoot> prompt type dis enter. You have 15 seconds to complete. This disables the loading feature of bootloader. For more information search the Pro_Guide.pdf document for \#!DM.

$\square$ Type timeout 60 enter. This will change the network startup timeout to 60 seconds. With this change the DeviceMaster Pro will reboot and connect properly when integrated into a complex network switch.

\section{C.05 TCP/IP Socket Connection Setup Only:}

Areva's E-terracontrol has the option to connect to socket ports. An IP address must be defined for the DeviceMaster Ethernet port, and a unique port\# must be assigned to each com port.

- From PortVision's startup window click on the Web Manager button. An Internet Explorer window will come up and connect to the management 
interface of the Device Master Pro.

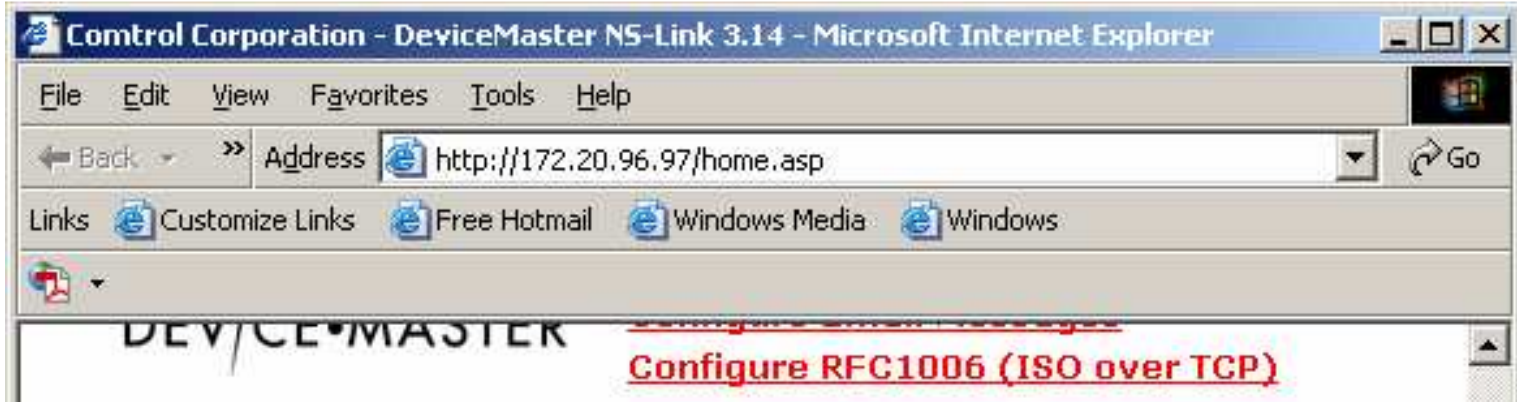

TCP Connection Status

Enabled: Yes Yes Yes Yes Yes Yes Yes

Local: $\quad 0.0 .0 .0: 00.0 .0 .0: 00.0 .0 .0: 00.0 .0 .0: 00.0 .0 .0: 00.0 .0 .0: 00.0 .0 .0$

Remote: $\quad 0.0 .0 .0: 00.0 .0 .0: 00.0 .0 .0: 00.0 .0 .0: 00.0 .0 .0: 00.0 .0 .0: 00.0 .0 .5$

Rx bytes: $00 \begin{array}{llllll}0 & 0 & 0 & 0 & 0 & 0\end{array}$

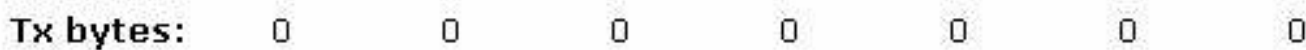

Serial Status

Mode: $\quad$ RS-232 RS-232 RS-232 RS-232 RS-232 RS-232 RS-232

Baud: $\quad 960096009600 \quad 9600 \quad 9600 \quad 9600 \quad 9600$

Parity: none none none none none none none

$\begin{array}{llllllll}\text { Data Bits: } & 8 & 8 & 8 & 8 & 8 & 8 & 8\end{array}$

$\begin{array}{llllllll}\text { Stop Bits: } & 1 & 1 & 1 & 1 & 1 & 1 & 1\end{array}$

Flow: none none none none none none none

DTR: socketon socketon socketon socketon socketon socketon socket

EOL: none none none none none none none

$\begin{array}{lllllll}\text { Timeout: } 0 & 0 & 0 & 0 & 0 & 0 & 0\end{array}$

TCP Connection Configuration

Listen Port: $8000 \quad 8001 \quad 8002 \quad 8003 \quad 8004 \quad 8005 \quad 8006$

Connect To: 0.0.0.0:0 0.0.0.0:00.0.0.0:00.0.0.0:00.0.0.0:00.0.0.0:00.0.0.0

Connect On: never never never never never never never

Disconn on: never never never never never never never

Idle Timeout: -

$1+$ 
C.05.01 Port 1 example configuration

\begin{tabular}{|c|c|c|c|c|c|c|}
\hline \multicolumn{5}{|c|}{ SComtrol Corporation - DeviceMaster RTS NS-Link 3.14 - Microsoft Internet Explarer } & \multicolumn{2}{|c|}{$-|a| x$} \\
\hline \multicolumn{5}{|c|}{ File Edit Yiew Favorites Iools Help } & & (해 \\
\hline \multicolumn{5}{|c|}{ W Back - " Address / hette://172.20.96.97/editPort.asp?portNum=0 } & $\nabla$ & ते Go \\
\hline \multicolumn{7}{|c|}{ 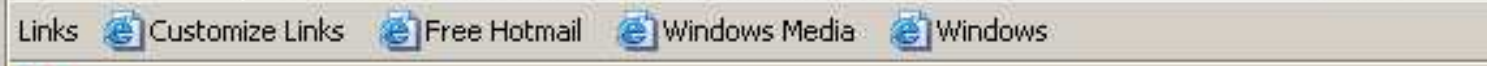 } \\
\hline \multicolumn{7}{|l|}{ 2. } \\
\hline \multicolumn{5}{|c|}{ Edit Port 1 Configuration } & & $\triangle$ \\
\hline \multicolumn{7}{|c|}{ Serial Configuration } \\
\hline \multicolumn{7}{|c|}{ Mode: $\quad$ RS-232 } \\
\hline \multicolumn{7}{|c|}{$9600 \rightleftharpoons$} \\
\hline \multicolumn{7}{|c|}{ Parity: $\quad$ none $\square$} \\
\hline \multicolumn{7}{|l|}{ Data Bits: } \\
\hline \multicolumn{7}{|l|}{ Stop Bits: } \\
\hline \multicolumn{7}{|l|}{ Flow: } \\
\hline \multicolumn{7}{|c|}{ socketon $=$} \\
\hline \multicolumn{7}{|c|}{ disabled $\square$} \\
\hline \multicolumn{7}{|c|}{ Input Timeout: $\longdiv { 0 } \mathrm { ms }$} \\
\hline \multicolumn{7}{|c|}{ TCP Connection Configuration } \\
\hline Enable: & $\sqrt{ }$ & & & & & \\
\hline Listen: & $\sqrt{\nabla}$ & Por & $\mathrm{t}: \longdiv { 8 0 0 0 }$ & & & \\
\hline Connect To: & & 0.0 .0 .0 Por & $t: \longdiv { 0 }$ & & & \\
\hline Connect On: & $\Gamma$ Always & $\Gamma$ Data & $\ulcorner\mathrm{DSR}$ & $\ulcorner\mathrm{CD}$ & & \\
\hline Disconnect On: & $\Gamma$ Idle & $\Gamma$ No DSR & $\ulcorner$ No $\mathrm{CD}$ & & & \\
\hline Idle Timer: & $\overline{300}$ & & & & & \\
\hline UDP Connection & Configuratio & & & & & \\
\hline$\Gamma$ Enable Serial & To Ethernet & & & & & $=$ \\
\hline (9) Done & & & & Internet & & \\
\hline
\end{tabular}


Port 1 configuration continued

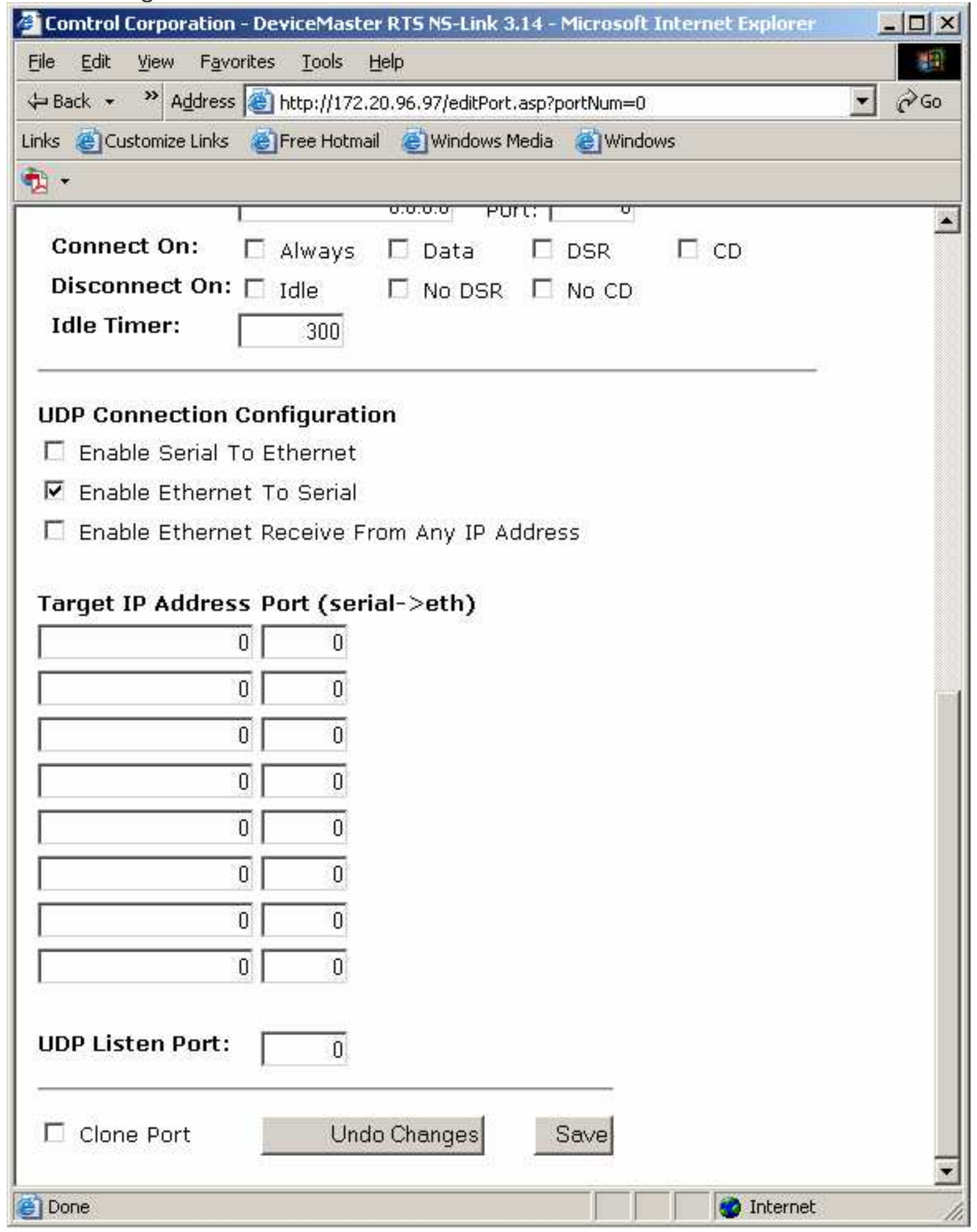

This completes the Comtrol DeviceMaster Pro setup. 